UNIVERSIDADE FEDERAL FLUMINENSE

INSTITUTO DE MATEMÁTICA E ESTATÍSTICA

LANTE - Laboratório de Novas Tecnologias de Ensino

O ENSINO HÍBRIDO NA FORMAÇÃO INTEGRAL DO SER

MARLUCI NUNES PINHEIRO

VOLTA REDONDA / RJ

2016 


\section{O ENSINO HÍBRIDO NA FORMAÇÃO INTEGRAL DO SER}

Trabalho de Final de Curso apresentado à Coordenação do Curso de Pós-graduação da Universidade Federal Fluminense, como requisito parcial para a obtenção do título de Especialista Lato Sensu em Planejamento, Implementação e Gestão da EAD.

Aprovada em Agosto de 2016.

\section{BANCA EXAMINADORA}

Prof. Cristiano Bezerra- Orientador

$$
\text { UFF }
$$

\section{Prof. Nome}

Sigla da Instituição

Prof. Nome

Sigla da Instituição 


\section{DEDICATÓRIA}

Dedico este trabalho a meus filhos Juliana e Lucas pelo apoio recebido, especialmente nos momentos em que estive ausente em função dos estudos e pesquisas. Impulsionando-me para frente, são luzes da minha alma. Companheiros desta e de outras vidas. 
A Deus, que nos criou e foi criativo nesta tarefa. Sev fôlego de vida em mim me foi sustento e me deu coragem para questionar realidades e propor sempre vm novo mundo de possibilidades.

Ao meu marido Carlos Fernandes, que com sua intelectualidade e presteza linguística foi meu porto seguro nos momentos em que compartilhamos ideias.

Aos meus queridos pais Darcio e Maria Lucia, que sempre me incentivaram nos estudos e tudo fizeram para que eu pudesse chegar aqui.

À querida Diretora Denise Telles Menchise por abrir portas e janelas à aprendizagem criativa e inovadora.

À dedicadíssima professora Rosemary por acreditar em minhas propostas educativas e me apoiar todo o tempo em que estivemos juntas.

Aos companheiros de trabalho pelo incentivo e apoio que tanto fortaleceram o meu caminhar, agregando certezas e valores. 


\section{RESUMO}

Este trabalho tem como objetivo apresentar o resultado de ações educativas específicas para aprendizagem baseada em metodologias ativas de Ensino Híbrido, que tem na modalidade EaD um suporte essencial para sua dinâmica. Descreve as etapas de 04 estudos de caso em diferentes níveis de escolaridade (Ensino Fundamental, Ensino Médio e Ensino Superior) focados nos seguintes aspectos: o processo avaliativo; a personalização da educação; aprendizagem colaborativa; cultura escolar; protagonismo do aluno; professor como mediador da aprendizagem e ambiente virtual de aprendizagem (AVA). Para isso, lançamos mão de recursos digitais, como os aplicativos Zaption, Plickers, Flubaroo e Google Forms, além da plataforma Google e da metodologia híbrida "Sala de Aula Invertida". Por meio do desenvolvimento do presente estudo, foi possível observar que a tecnologia viabiliza os métodos avaliativos por meio de recursos diversos, como os sistemas de cooperação e os registros individuais de resultados, mas que o papel docente permanece definido como de grande relevância no universo que envolve a Educação para o Século XXI, devendo sua formação ser permanente; imprescindível e focada em Competências Sociocognitivas que envolvem sua área de conhecimento acadêmico, mas também as Tecnologias Digitais de Comunicação e Informação (TDCI) e as Competências Socioemocionais tão necessárias para as práticas educativas de formação integral do ser.

Palavras-chave: Ensino Híbrido; Metodologias Ativas; Educação para o Século XXI 


\section{SUMÁRIO}

$\mathrm{N}^{\mathrm{o}}$ da página

1 - Introdução

1.1 - Justificativa 9

$\begin{array}{ll}1.2-\text { Objetivos } & 10\end{array}$

$\begin{array}{ll}1.2 .1 \text { - Objetivo Geral } & 10\end{array}$

$\begin{array}{ll}1.2 .2 \text { - Objetivos Específicos } & 10\end{array}$

$\begin{array}{ll}1.3 \text { - Metodologia } & 10\end{array}$

1.4 - Organização do Trabalho 11

2 - Pressupostos Teóricos 12

2.1 - Fundamentos Legais $\quad 12$

2.2 - Século XXI: Gestão das Metodologias Ativas 12

2.3 - Ensino Híbrido: Personalizando a Educação através das 14 Metodologias Ativas

3 - Vivenciando o Ensino Híbrido 19

3.1 - Detalhamentos da elaboração do material da pesquisa 
3.1.2 - Plickers

3.2 - Análise dos dados

3.2.1 - Análise comparativa dos resultados gerais de desempenho entre as turmas A e B

4 - Considerações Finais

5 - Referências

6 - Anexos 


\section{Introdução}

Este trabalho de conclusão de curso conta com partes de produção realizadas coletivamente, na qual cada aluno colaborou na construção dos pressupostos teóricos, justificativas, objetivos e metodologia.

A partir de estudos e análises coletivas, cada aluno pode desenvolver sua pesquisa individual tendo como embasamento central os recursos didáticos relacionados com ambientes virtuais e mídias na educação no contexto do Ensino Híbrido e suas fundamentações teóricas.

A pesquisa de Mara de Moura Machado apresenta uma análise criteriosa sobre o uso de alguns recursos midiáticos específicos para os processos avaliativos. O trabalho de Wallace de Paula Machado foca na análise dos resultados de aprendizagem a partir do uso de aplicativo para a dinamização de vídeos educativos. Já Márcio Ronner Monteiro Matias aborda a construção de um panorama pedagógico-cultural sobre as potencialidades e limitações do uso de Ambientes Virtuais de Aprendizagem (AVA). Num sentido mais amplo, Marluci Nunes Pinheiro engloba todas as dimensões acima analisadas (recursos midiáticos educativos, AVA e processos avaliativos) propondo suas aplicabilidades na perspectiva do Ensino Híbrido por meio de Metodologias Ativas (neste caso, a chamada "Sala de Aula Invertida").

Vale lembrar que a educação, ao longo do século XX, sofreu significativas mudanças, tendo as tecnologias de comunicação como um de seus principais agentes representados, a princípio, pelo rádio e pela televisão.

Durante a Guerra Fria, por interesses militares, foi criada a internet.

Naquela época ninguém imaginava o grande impacto que tal invenção causaria na vida planetária, já que nos anos 80 ela também passaria a atender às necessidades comerciais do usuário comum.

Embora esses avanços tenham significado um salto qualitativo na capacidade comunicacional e nos processos educativos, um grande hiato ainda permanecia, separando o desenvolvimento tecnológico e o professor, pois, enquanto inúmeros fatores, ao longo dos anos, direcionavam a humanidade para a era do automatismo e das informações instantâneas, o professor, em geral, se mantinha na posição centralizadora do conhecimento e o computador ainda era apenas uma versão modernizada da lousa de giz.

Somente com o advento da moderna informática é que a educação rompeu em grande parte com o tradicional. A internet, de forma ampla e democrática, abriu infinitas oportunidades em se tratando de acesso e armazenamento das informações. Com isso, novos ajustes foram dados às modalidades de ensino, incluindo a $\mathrm{EaD}$ que hoje se apresenta em desenhos versáteis a fim de atender a público variado.

Segundo Alves (2011, p. 01):

A Educação a Distância, modalidade de educação efetivada através do intenso uso de tecnologias de informação e comunicação, onde professores e alunos estão separados físicamente no espaço e/ou no tempo, está sendo cada vez mais utilizada na Educação Básica, Educação Superior e em cursos abertos, entre outros.

Em outras palavras, os processos educativos da atualidade focados no aprendizado por competências devem garantir aos aprendizes o desenvolvimento de habilidades diversas para que estes se preparem para viver no mundo de forma interativa, autônoma, criativa e protagonista.

A partir dessas proposições, este TFC, por meio de um projeto de pesquisa de campo, apresenta informações essenciais que orientam e comprovam a eficiência e eficácia de ambientes virtuais e das mídias de comunicação nos processos híbridos de aprendizagem, no qual a modalidade EaD também se faz presente.

Todo esse estudo é fundamentado em literatura bastante recente de diversos autores, com 
ênfase nas pesquisas mais atuais realizadas no Brasil.

Os resultados obtidos em uma turma do Ensino Médio por meio da aplicação da metodologia "Sala de Aula Invertida" com uso de recursos digitais (aplicativos), convida o leitor para uma análise reflexiva sobre o papel do professor, dos processos avaliativos e que tipo de aluno queremos formar para a atualidade.

Nessa perspectiva, a personalização do ensino é assunto tratado aqui com destaque e está intrinsicamente ligada aos novos paradigmas da avaliação da aprendizagem que, por sua vez, se conectam a uma nova visão quanto à organização física da sala de aula e a valorização das atividades colaborativas e em pares, não necessariamente realizadas nos mesmos tempo e espaço.

Tudo isso porque os professores (em sua maioria pertencentes à geração "X") já não se conectam apenas com as conhecidas gerações "Y" e "Z."

Hoje uma nova geração se desponta: a geração Alpha: totalmente imersa nesse novo conceito de aprendizagem híbrida e, por isso, muito mais exigente.

Segundo estudiosos, esta geração será caracterizada pela instrução e educação. Nenhuma outra teve tanto acesso ao conhecimento humano como esta que agora começa a se formar.

Essas novas estruturas sentidas na prática pelos educadores fazem parte de um movimento universal e não há outro caminho a não ser participar dessas mudanças.

A tecnologia educacional por si só nada modifica as práticas educativas, mas é ferramenta valiosa para a construção de um novo lugar para a escola.

\subsection{Justificativa}

O Ensino Híbrido faz parte de um conjunto de mudanças ocorridas em grande parte dos serviços e processos de produção de bens que incorporaram os recursos das tecnologias digitais. Sendo assim, não pode ser considerado como modismo que aparece de repente na educação. É algo que veio para ficar, conforme afirma José Armando Valente, professor titular do Departamento de Multimeios, Mídia e Comunicação do Instituto de Artes da Unicamp.

Nesse sentido, soluções educacionais inovadoras com uso das Tecnologias Digitais de Informação e Comunicação (TDCI) vieram contribuir para a superação de uma gama de problemas relacionados aos processos avaliativos da aprendizagem e aos ruídos de comunicação entre professor e aluno, contribuindo também para aulas mais atrativas e ajustadas à educação para o século XXI, conforme nos apontam Jacques Delors (2002) e sua comissão no Relatório da UNESCO da Comissão Internacional, onde defendem o conceito de educação integral para o desenvolvimento pleno do ser humano. Em outras palavras, os processos educativos da atualidade devem garantir aos aprendizes o desenvolvimento de habilidades diversas para que estes se preparem para viver no mundo de forma interativa, autônoma, criativa e protagonista.

A partir dessas proposições, o presente trabalho (tendo como ponto de partida os resultados da pesquisa realizada por Clayton M. Christensen (2012) e sua equipe, bem como os artigos compilados e organizados por Lilian Bacich, Adolfo Tanzi Neto e Fernando de Mello Tevisani (2015), além de outras obras acadêmicas que compõem uma vasta bibliografia, vem apresentar informações essenciais que orientam e comprovam a eficiência e eficácia de ambientes virtuais e das mídias de comunicação nos processos educativos híbridos, em especial o subtema "Sala de Aula Invertida". 


\subsection{Objetivos}

\subsubsection{Objetivo geral:}

Propor formas alternativas eficientes e eficazes nos processos educativos híbridos (presencial e on line) a partir do uso das Tecnologias Digitais de Comunicação e Informação (TDCI) com ênfase na Personalização da Educação através de Metodologias Ativas de aprendizagem e, em especial, no Peer Instruction (aprendizagem pelos pares), um exemplar dessa forma de ensino-aprendizagem.

\subsubsection{Objetivos específicos:}

1. Elucidar as vantagens do Letramento Digital na aprendizagem híbrida, a partir de aplicativo específico (Zaption) para uso de recursos audiovisuais, como ferramenta complementar para aulas no Ensino Fundamental II, bem como seu impacto no desempenho das turmas avaliadas.

2. Analisar processos avaliativos a partir do uso das ferramentas Google Form e Flubaroo em plataforma Moodle no Ensino Fundamental II.

3. Levantar dados, por meio do uso de aplicativos em AVA e em celular (Plickers), que comprovem, por amostragem, o grau de eficiência e eficácia do uso do Ensino Híbrido (do tipo Sala de Aula Invertida) no Ensino Médio, em relação às metodologias tradicionais de aprendizagem.

4. Analisar os resultados alcançados entre alunos que vivenciaram o Ensino Híbrido e aqueles que desenvolveram atividades sobre os mesmos conteúdos, mas de forma tradicional.

5. Analisar a funcionalidade do uso da plataforma Moodle em atividades de Ensino Híbrido no Ensino Superior.

\subsection{Metodologia}

No aprofundamento da pesquisa de Mara de Moura Machado foi utilizado o estudo de caso em uma turma de $9^{\circ}$ ano do Ensino Fundamental II, na disciplina de Ciências, no Colégio Municipal Vereador Paulo Basílio de Oliveira, Barra Mansa, Estado do Rio de Janeiro, onde os alunos, através de ambiente virtual de aprendizagem Moodle realizaram quizzes com uso do aplicativo Google Forms, bem como do Flubaroo para avaliação dos resultados. O Flubaroo gera uma planilha com todas as respostas dos alunos pontuando cada questão correta individualmente e também um percentual de acertos. Com relação a esse percentual, além de gerar um total por alunos, gera um total geral por questão e ainda destaca as questões que tiveram menos de $60 \%$ de acertos. Assim, a partir de análise quantitativa, objetivou-se visualizar as habilidades e competências que precisavam de ações para que os conceitos fossem trabalhados de outras formas a fim de obter a qualidade da aprendizagem desejada.

Já no trabalho de Wallace de Paula Machado, foi utilizado o aplicativo Zaption em uma turma de $7^{\circ}$ ano do Ensino Fundamental II, na disciplina de Ciências, no Colégio Municipal Vereador Paulo Basílio de Oliveira, Barra Mansa, Estado do Rio de Janeiro. O Zaption é uma ferramenta disponível em ambiente virtual de aprendizagem - AVA - que permite a inserção de vídeos do Youtube, incluindo intervenção para reflexão e questionamentos durante a apresentação dos vídeos. Essa apresentação será disponibilizada pelo próprio aplicativo. Os discentes foram convidados a responder estes questionamentos no próprio Zaption, onde se analisou de forma quantitativa o desempenho de cada aluno apontado pelos gráficos do programa. Após a exibição 
dos vídeos, em uma turma foram aplicadas avaliações somativas e comparadas com a turma que não utilizou os objetos educacionais acima identificados. $\mathrm{Na}$ análise final dessa pesquisa, comparou-se o nível de desempenho entre os resultados da turma que participou dessa pesquisa com a outra que não usou os mesmos recursos, a fim de avaliar quantitativamente a eficiência e eficácia do Ensino Híbrido.

Da mesma forma, Márcio Ronner Monteiro Matias realizou sua pesquisa com os alunos (cadetes) do $3^{\circ}$ ano da Academia Militar Agulhas das Negras (AMAN), situada no município de Resende, Estado do Rio de Janeiro, para os quais a disciplina de Metodologia do Ensino Superior (MES), que, usualmente, é ministrada na modalidade presencial, foi ofertada de forma complementar na plataforma Moodle. Nesse contexto, foram utilizados atividades e recursos que o referido Ambiente Virtual de Aprendizagem (AVA) propicia, tais como, a possibilidade de disponibilizar conteúdos (aulas em Powerpoint) e a criação de fóruns de dúvida, mas de forma personalizada ao público-alvo. Com isso, verificou-se/ratificou-se, de forma quantitativa, a ocorrência da melhoria do processo de ensino-aprendizagem ofertado por meio desse desenho, em detrimento da turma do ano de 2015 onde as atividades foram realizadas sem o referido AVA.

Marluci Nunes Pinheiro realizou seu estudo de caso no Instituto de Cultura Técnica, no município de Volta Redonda, Estado do Rio de Janeiro, em uma turma de $1^{\circ}$ ano do Ensino Médio, na disciplina de Química, com ênfase no método híbrido denominado "Sala de Aula Invertida".

Aos alunos desta turma foi proposto iniciar o assunto da aula ainda em casa (ou no laboratório de informática), com auxílio do aplicativo Zaption, onde foi postado um vídeo problematizador a fim de que os mesmos buscassem de forma autônoma a solução para a situação dada.

No dia seguinte, já em sala de aula, os alunos foram orientados a apresentar suas dúvidas e possíveis soluções de forma colaborativa, ou seja, em duplas. Coube ao professor, em outro momento, organizar os "times" conforme o nível de desempenho apontado nos gráficos do programa Zaption.

Ao final, uma avaliação de cunho quantitativo, com uso do aplicativo Plickers, foi realizada para medir o resultado geral da assimilação dos conceitos propostos.

Ressaltamos que em todos os estudos de caso houve uma segunda turma "controle" onde o mesmo professor desenvolveu assuntos idênticos, porém de forma tradicional, pois pretendemos realizar análise comparativa entre os resultados ocorridos em ambas as turmas, a fim verificar os impactos do uso do Ensino Híbrido em sala de aula.

\subsection{Organização do Trabalho}

O presente trabalho está organizado em quatro capítulos. O capítulo 1 apresenta a introdução do trabalho, pontuando os principais assuntos abordados por esta pesquisa; a justificativa, o objetivo geral; os objetivos específicos e a metodologia aplicada. O capítulo 2 apresenta de forma descritiva os pressupostos teóricos de grande relevância para esse estudo e que, ao longo dos anos, significou suporte e fortalecimento da modalidade $\mathrm{EaD}$ no panorama educacional brasileiro. Além disso, aborda questões vinculadas à gestão das Metodologias Ativas e seu papel na perspectiva do Ensino Híbrido, com destaque para a personalização do ensino. $\mathrm{O}$ capítulo 3 traz para o chão da escola toda a teoria abordada, apresentando os resultados da pesquisa por meio de análises estatísticas e relatórios que analisam os impactos e aplicabilidades de ferramentas específicas em Ensino Híbrido e Metodologias Ativas. Por fim, o capítulo 4 apresenta as conclusões do trabalho. Em síntese, os capítulos do TFC apresentam partes construídas de forma colaborativa entre os membros do grupo e outras partes individuais mais específicas. 


\section{Pressupostos Teóricos}

\subsection{Fundamentos Legais}

Caracterizamos o modelo de Educação a Distância (EaD) tendo como premissa os fundamentos baseados no estudo de Mello (2007).

Trazendo-o para o cerne desta pesquisa focada no Ensino Híbrido, cuja estrutura tem a modalidade $\mathrm{EaD}$ como um dos principais suportes para seu funcionamento, e acompanhando o raciocínio da renomada educadora - que afirma que a escrita veio não somente para viabilizar o tempo-espaço da comunicação, mas também, e principalmente, para legitimar a oralidade de seus interlocutores - inferimos que, da mesma forma, em se tratando do Ensino a Distância, o desenvolvimento da legislação que vem regulamentando a $\mathrm{EaD}$ ao longo dos anos é fator preponderante para que certa estabilidade ocorra nesta inovadora e quase instantânea forma de se comunicar e mediar a Educação. Somente assim essas normatizações podem ser reavaliadas e, por vezes, refeitas de tempos em tempos, a fim de percorrer de forma extremamente democrática o trajeto pelo qual aqui chegamos, conferindo-lhe, cada vez mais, credibilidade e minimizando, paulatinamente, os estigmas que ainda a situam numa posição menos privilegiada frente à modalidade presencial.

Revisamos em Alves (2011) importantes conceitos dentro da modalidade EaD elaborados por alguns autores e enumerados por alguns acontecimentos e instituições que se tornaram marcos históricos para a consolidação da atual Educação a Distância no Brasil e no mundo.

A presente pesquisa também se ampara na Lei de Diretrizes e Bases da Educação Nacional (LDB) de 1996 (Lei Federal no 9.394), principalmente em seu artigo $\mathrm{n}^{\circ}$ 80, o qual vem incentivar o desenvolvimento e a veiculação de programas de ensino a distância em todos os níveis e modalidades de ensino e de educação continuada, bem como autorizar sua formatação no que tange os seguintes aspectos: sua abertura e regime especiais; requisitos para a realização de exames e registros de diplomas; normas para produção, controle e avaliação, com abertura para cooperação e integração entre os diferentes sistemas.

Dentre tantos outros decretos que precederam o de 1998, ressalta-se o Decreto $n^{\circ} 5.622$ de 2005, que se destaca por seu caráter inovador ao permitir o desenvolvimento de uma política nacional de $\mathrm{EaD}$ à qual foram fixadas diretrizes norteadoras para o sistema de ensino do país.

Ao explorar alguns pontos importantes da legislação brasileira da EaD no Brasil, percebemos a nobre e distinta preocupação do governo em democratizar de forma sistematizada essa modalidade de ensino. Não há outro caminho. Devemos seguir em direção às novas formas de aprendizagem que o mundo globalizado encerra.

\subsection{Século XXI: Gestão das Metodologias Ativas}

A gestão da tecnologia, sem a qual não há Educação à Distância, juntamente com os órgãos normatizadores, precisa estimular o envolvimento dos aprendizes que se beneficiam dessa modalidade de desenvolvimento. É nesse ponto que se instala o tema central de nossa pesquisa.

Segundo Alves (2011) esta modalidade de educação é conceituada por diversos autores. A ênfase de cada autor, os diversos acontecimentos históricos e as variadas instituições, mencionadas neste trabalho, mostram que a Educação a Distância oferece oportunidades que, pelo modelo presencial, seriam difíceis ou impossíveis de se atingir, pois possui uma ampla abrangência e magnitude não somente no nosso país, mas em todo o mundo.

Nessa perspectiva, encontramos nos estudos de Valente e do grupo Bacich, Neto e Trevisani - que, por sua vez, se apoiaram num conjunto de artigos de diversos especialistas na vertente das teorias desenvolvidas pela equipe pioneira de Clayton M. Christensen (Harvard) subsídios para o desenvolvimento de nossa pesquisa. 
Segundo Valente (2014) "há várias maneiras de se combinar aulas à distância e presenciais, o que denominamos de atividades híbridas (blendeded learning)."

$\mathrm{O}$ autor aborda essas metodologias como "ativas" para se referir às práticas educativas onde o aluno é o agente principal responsável por sua aprendizagem, dando ênfase à importância das Tecnologias Digitais de Comunicação e Informação (TDCI) como seu principal suporte.

A partir dessa análise compreendemos que, dentro dessa modalidade de ensino, independentemente do desenho escolhido para o uso das metodologias híbridas/ ativas de aprendizagem, o cooperativismo vem substituir o individualismo, ou seja, não há mais a divisão entre quem aprende e quem ensina, posto que todos precisarão fazer parte na construção da aprendizagem, seja o assunto que for. Mais adiante, abordaremos de forma mais específica os fundamentos da metodologia ativa selecionada para essa pesquisa.

O professor, por sua vez, deixará de exercer o papel central da aprendizagem e passará a ser o mediador de cada ação. Portanto, para que isso ocorra, é necessário que o ambiente de aprendizagem seja transformado e adequado a essa nova dinâmica. Tanto no ensino presencial e, principalmente, no ensino a distância, o docente/tutor tem papel fundamental no processo ensinoaprendizagem.

Dessa forma, segundo Silva (2015) e Oliveira (2016), o professor deve motivar seus alunos a usar as ferramentas $\mathrm{EaD}$, bem como ter consciência de que aquele é agente decisivo contra a evasão escolar.

Segundo Schneider, a partir da elaboração dos Planos Curriculares Nacionais (PCNs), em 1998, e, posteriormente com os Parâmetros Curriculares Nacionais do Ensino Médio (2000), os professores tiveram a oportunidade de refletir sobre a necessidade de um ensino que valorizasse o pensamento crítico, desenvolvido a partir da interação entre os alunos, permitindo-lhes o contato com diferentes formas de pensar e ampliando sua autopercepção como cidadãos no contexto em que estão inseridos.

Tal afirmativa corrobora com o relatório de Delors que afirma que a Educação não deve ser concebida apenas com foco nos estudos sistematizados, mas também deve privilegiar outros conteúdos e formas de aprendizagem. Nesse sentido, a educação para o século XXI deve implementar ações que estimulem o ser humano a se desenvolver de forma integral.

Delors (2002, p.89 e 90) ainda complementa:

\begin{abstract}
Para poder dar resposta ao conjunto das suas missões, a educação deve organizar-se em torno de quatro aprendizagens fundamentais que, ao longo de toda a vida, serão de algum modo para cada indivíduo, os pilares do conhecimento: aprender a conhecer, isto é adquirir os instrumentos da compreensão; aprender a fazer, para poder agir sobre o meio envolvente; aprender a viver juntos, a fim de participar e cooperar com os outros em todas as atividades humanas; finalmente aprender a ser, via essencial que integra as três precedentes. É claro que estas quatro vias do saber constituem apenas uma, dado que existem entre elas múltiplos pontos de contato, de relacionamento e de permuta [...]. Mas, em regra geral, o ensino formal orienta-se, essencialmente, $\mathrm{e}$ não exclusivamente, para o aprender a conhecer e, em menor escala, para o aprender a fazer. As duas outras aprendizagens dependem, a maior parte das vezes, de circunstâncias aleatórias quando não são tidas, de algum modo, como prolongamento natural das duas primeiras. Ora, a Comissão pensa que cada um dos "quatro pilares do conhecimento" deve ser objeto de atenção igual por parte do ensino estruturado, a fim de que a educação apareça como uma experiência global a levar a cabo ao longo de toda a vida, no plano cognitivo como no prático, para o indivíduo enquanto pessoa e membro da sociedade.
\end{abstract}

Outro fator de destaque na gestão do trabalho com atividades em EaD (aqui em especial no universo das metodologias ativas) é a "netiqueta" que, desde o primeiro momento, deve ser especificada. Isto é, o que serão direitos e deveres dos alunos. As referidas normas devem ser 
elaboradas de acordo com o público-alvo e terem regras claras para aqueles que infringirem as normas de conduta.

$\mathrm{Na}$ elaboração das questões avaliativas em AVA também se deve dispensar cuidado especial a seus tipos (múltipla escolha, completamento, resumo).

Conforme Ramos (2013) nos dias atuais uma tendência vem se firmando: o uso da peer evaluation (avaliação aos pares), a qual demonstra ser uma ferramenta interessante e útil em se tratando de turmas numerosas.

Como se constata, o papel do professor sofreu, e vem sofrendo, muitas transformações, que exigem novos paradigmas que não estão simplesmente nos conteúdos curriculares em si, mas, principalmente, na forma de se ensinar.

\subsection{Ensino Híbrido: Personalizando a Educação através das Metodologias Ativas}

Para os fins dessa pesquisa, selecionamos um dos diversos tipos de modalidades de Metodologias Ativas, denominada "Sala de Aula Invertida", por entendermos ser esta de fácil aplicação em muitas escolas brasileiras (consideradas não disruptivas, ou seja, dentro do padrão tradicional de educação aplicado na maioria dos estabelecimentos de ensino no Brasil) a partir do conceito peer instruction apresentado por Mazur e conhecido no Brasil em âmbito nacional como "aprendizagem por pares".

A Sala de Aula Invertida (Flipped Classroom) utiliza metodologia fundamentada nas teorias da blendeded learning.

Segundo Valente (2014, p.84):

[...] o conteúdo e as instruções devem ser elaborados especificamente para a disciplina ao invés de usar qualquer material que o aluno acessa na internet. Além disso, a parte presencial deve necessariamente contar com a supervisão do professor, valorizar as interações interpessoais e ser complementar às atividades on-line, proporcionado um processo de ensino e de aprendizagem mais eficiente, interessante e personalizado.

Staker e Horn (2012) definem um quadro com modelos que categorizam a maioria dos programas de ensino híbrido ou blended: flex, blended misturado, virtual enriquecido e rodízio. É neste último (que está subdividido em 4 subgrupos) que encontramos a modalidade "Sala de Aula Invertida" (o $4^{\circ}$ subgrupo).

No curso de nossas pesquisas, encontramos em Fontes e Silva (2004, apud MARTINHO e POMPO, 2009, p.529) orientações pedagógicas e de reestruturação curricular adequadas e consonantes à legislação brasileira, para que, através da potencialização das TDCI, o aluno deixe de ser um sujeito passivo e passe a explorar as formas de procurar, selecionar, analisar e discutir informação.

Em Franco (2007, p.2), identificamos os possíveis ganhos pedagógicos na mediação entre o conhecimento real e o virtual, tanto para o aluno quanto para o professor, pois tal ação pode transcender o esperado e impactar diretamente na forma como o aluno vê a escola.

Consequentemente, a aprendizagem é estimulada e o indivíduo se torna protagonista de seu aprendizado, o que identificamos também como de fundamental importância para os trabalhos desenvolvidos pela Fundação Lemann do Brasil, uma das pioneiras em nosso país na divulgação do Ensino Híbrido. Especialmente quando se refere à parceria com a Khan Academy (espaço virtual de aprendizagem que oferece exercícios, vídeos de instrução e um painel de aprendizado personalizado que habilita os estudantes a aprender no seu próprio ritmo dentro e fora da sala de aula). 
Inspirados em todos esses estudos, sentimos também a necessidade de definirmos um espaço virtual de aprendizagem para a realização de nossos estudos de caso. Para isso, fomos buscar em Pereira (apud, DUTRA e ARRUDA, 2013, p. 816-820); Santos (apud, MARTINHO e POMBO, 2009, p. 530); Okada (2009, p.55-91); Cruz (apud, FRANCO et al., 2007, p.4) e Sobreira (2013, p.74-87), subsídios para o desenvolvimento de atividades em plataforma virtual de aprendizagem (AVA).

A montagem dos Ambientes Virtuais de Aprendizagem (AVA) no âmbito da Educação a Distância $(\mathrm{EaD})$ é de fundamental importância, à medida que eles são o principal canal de comunicação com o cursista.

No contexto da elaboração dos cursos EaD, é necessário que sejam observados os seguintes fatores: papel do docente/tutor; discriminação das normas de convivência (netiqueta); benchmarking com outros AVA; cuidados no designer dos cursos; material didático (criação/edição de vídeos/ áudios e a criação de livros digitais); criação de conteúdos para as aulas; avaliações (o que e como avaliar) e, finalmente, algumas ideias/ sugestões no uso do Moodle (foco de estudo desse trabalho).

Também foram analisados de forma comparativa outros AVA, como: AULANET, QUANTUM, UNIVERSITE, WEBCT e ADX, além de observamos os Cursos Online Abertos e Massivo, do inglês Massive Open Online Course (MOOCS) e sua dinâmica dentro da plataforma Moodle, além de diversos recursos oferecidos pelo GOOGLE.

Embora o Moodle seja um dos AVA mais utilizados mundialmente e apresente constantes atualizações, a cada dia surgem outros AVA com características bastante interessantes e significativas em relação aos apectos técnico e de designer, dentre os quais podemos exemplificar: o EDX, o Coursera e o Edmodo.

O AVA é a interface do curso com o aluno e, portanto, merece especial cuidado na sua elaboração, a fim de que signifique um ambiente atraente, organizado e interativo e, dessa forma, incentive e motive os cursistas para a aprendizagem.

Assim como o designer dos cursos, a criação do material didático necessita de cuidados na sua elaboração. Atualmente pode-se encontrar vários sites e programas especializados (gratuitos) para a criação/publicação de vídeos (Youtube; Camtasia); de áudios (Audacity) e de livros digitais (ibooks. Camaleo; Book Creator).

Os seguintes aplicativos foram acessados e analisados por nossa equipe, por considerarmos estes de grande relevância e aplicabilidade em nossa pesquisa: Zaption; Plickers; Audacity; Book Creator; Camaleo; Coursera e Edmodo).

No que se refere aos conteúdos para aulas online, existem softwares específicos para tal finalidade, como o Powerpoint do pacote Office, o iSpring e o Google Apresentações, que permitem a criação de conteúdos interativos, de multimídias e de avaliações.

A incorporação de recursos audiovisuais para a dinamização do AVA, foi outra ação que também passou por uma criteriosa escolha do grupo.

Nesse sentido, apresentamos uma série de cuidados que consideramos fundamentais para que o professor possa utilizá-los de maneira efetiva.

Conforme Rosa (2000, p.38), antes de qualquer aplicabilidade das mídias, os conceitos devem ser estudados a fim de se criar embasamento teórico e, consequentemente, segurança, tanto para o professor, como para o aluno, no momento de sua aplicação.

Segundo o mesmo autor:

Quando se usa imagem e som na sala de aula, um processo semelhante ocorre. Todo filme, slide, transparência, programa multimídia, etc. traz embutido, dentro de si, um processo de codificação definido pelo (s) autor (es) do produto audiovisual. Um filme, como um livro, deve passar por um processo de decodificação por parte de quem o vê. Esse processo deve ser apreendido tanto no que diz respeito às ações mecânicas necessárias para a sua compreensão 
(coordenação visual, p. ex.) como no que diz respeito à matriz cultural, em função da qual o produto existe e deve ser interpretado.

Ainda considerando nossa abordagem sobre o uso de recursos audiovisuais, vimos que o vídeo na educação, enquanto objeto educacional para $\mathrm{EaD}$, deve ampliar possibilidades e estimula a imaginação. Não para cobrir lacunas no tempo de aula.

O uso de recursos audiovisuais, se bem aplicados, também pode estimular a curiosidade e fomentar a pesquisa dos conteúdos curriculares trabalhados. $\mathrm{O}$ contrário disso significaria o fracasso no processo ensino-aprendizagem.

Santos e Mortmer (apud REZENDE, 2008, p.2) afirmam que com uma visão absolutamente verdadeira e acabada daquilo que se está aprendendo, os alunos, certamente, encontrariam dificuldades em aceitar novas alternativas para a resolução de determinados problemas. Portanto é necessário que os vídeos, bem os demais objetos educacionais, estimulem a curiosidade, problematizem os assuntos que serão trabalhados e até mesmo permitam a (re) construção pelos próprios alunos de novas possibilidades de aprendizado.

Em igual importância estão os direitos autorais de quem produz os vídeos e, portanto, a inserção destes em AVA deve seguir alguns cuidados.

Como afirma Pereira (apud, DUTRA e ARRUDA, 2013, p. 845-857):

[...] as inserções de vídeos em repositórios na internet ou nos ambientes virtuais de aprendizagem também são processos bastante simples. Contudo, alguns critérios devem ser observados, para que o vídeo possua certa qualidade, e algumas regras devem ser obedecidas para que o mesmo possa ser divulgado sem prejuízos a trabalhos de terceiros [...]

Outro fator de grande relevância na presente pesquisa é o fato de que, com o avanço das tecnologias, o professor necessita ter cautela ao reinventar sua metodologia, acompanhando as mudanças e a forma de abordar os conceitos presentes nos diversos componentes curriculares.

De acordo com Almeida (apud SOBREIRA, BORRALHO e OLIVEIRA, 2013, p.76):

[...] a utilização de tecnologias na escola e na sala de aula impulsiona a abertura desses espaços ao mundo e ao contexto, permite articular a situação global e local, sem, contudo, abandonar o universo de conhecimentos acumulados ao longo do desenvolvimento da humanidade [...]

Já no campo das atividades diagnósticas e avaliativas, da mesma forma, há que se cuidar para que o computador não substitua a pesquisa e o trabalho colaborativo, e o erro deve sempre significar um novo desafio.

Para Ponte (apud SOBREIRA, BORRALHO e OLIVEIRA, 2013, p.78), a ideia é fazer do computador um objeto de estudo.

Dessa afirmativa inferimos que o ciberespaço precisa significar um universo fecundo e compartilhado de infinitas possibilidades, tanto para quem ensina, como para quem aprende.

Nas avaliações EAD deve-se tomar o cuidado para que a atividade individual seja colaborativa. Daí a necessidade de se criar estratégias que avaliem a participação dos alunos enquanto time.

Seguindo essa linha de raciocínio, existem diversos aplicativos para a utilização de atividades avaliativas em AVA, mas, consideramos de grande importância reforçar o que Ramos (apud COSTA e FRANCO, 2005, p.2) diz sobre o erro. Este deve ser tratado como processo investigativo, um momento para reflexão. Não como punição.

Para Piaget (apud COSTA e FRANCO, 2005, p.2) o erro possibilita identificar o préconceito do aluno e a realizar intervenções para a aprendizagem de forma significativa.

Segundo Loiselle (apud COSTA e FRANCO, 2005, p.3): 
[...] na participação da produção no ambiente AVA o estudante conduz suas próprias operações de coleta de informações e não se coloca como um simples consumidor da informação [...] o dispositivo estimula os estudantes a desenvolverem um conteúdo próprio, por exemplo seu portfólio e também sua autonomia $[\ldots]$

Após atividades no AVA é possível verificar através de atividades presenciais, também com o uso de aplicativos, o nível do conhecimento assimilado pelos alunos. contínua.

A avaliação é parte do processo ensino-aprendizagem e deve ser realizada de forma

$\mathrm{Na} \mathrm{EaD}$ a avaliação tem características distintas em relação ao ensino-aprendizagem, haja vista que, via de regra, as avaliações são realizadas a distância.

Com as TDCI há grande possibilidade de realizar avaliações, correções automáticas e tabulações de dados de forma rápida e eficiente.

De posse dos resultados, o docente poderá verificar os cursistas com maiores dificuldades, bem como os conteúdos em que tiveram baixo nível de compreensão.

Nessa pesquisa, o Plickers, o Google Forms e o Flubaroo foram os aplicativos escolhidos para serem utilizados como ferramentas avaliativas, por entendermos serem de aplicação funcional.

O Plickers e outras ferramentas avaliativas, conforme Lúcio (2015, p.24):

[...] têm desenvolvido alguns aplicativos muito interessantes e úteis (além de bem fáceis de utilizar) para auxiliar o professor na identificação de fragilidades de suas turmas, a fim de focar em alguns pontos mais específicos da matéria lecionada. Muitos desses aplicativos são de uso restrito do professor em sala de aula (ou seja, não requerem que o aluno os possua). [...] eles se têm mostrado extremamente úteis e versáteis na aplicação de testes de verificação de aprendizagem, quiz, memorização de informações pontuais (sempre necessárias nos processos educacionais) e, principalmente, na identificação, verificação e no feedback de pontos ainda não muito compreendidos pelo estudante.

No Google Forms, conforme Mathias e Sakai (2013, p. 7-12):

O levantamento de dados e opiniões podem ser facilmente realizados [...] conhecendo algumas possibilidades do Google Forms pode-se perceber facilmente as grandes vantagens do seu uso, mas também há algumas limitações, podemos citar o fato de o Google Forms ainda não aceitar a inserção de imagens em suas questões. Uma forma de contornar este problema é fazer solicitar um link de compartilhamento para ela e inserir a URL no enunciado da questão, informando que a pergunta se refere à imagem disponível no citado link [...] A análise dos dados coletados tem por finalidade fornecer a maior quantidade de informações que subsidiarão as ações de melhoria pedagógica, administrativa ou infraestrutural, através de um índice de satisfação discente (ISD) calculado utilizando-se a tabela $\mathrm{z}$ de uma distribuição normal, o que é justificado estatisticamente pelo Teorema do Limite Central.

Já o Flubaroo, conforme Mendes (2015, p. 79) permite a correção de avaliações do tipo múltipla escolha, a produção de relatórios e envio dos resultados por e-mail para cada usuário, que enviou sua avaliação. 
É preciso conhecer bem as ferramentas no AVA para que possamos explorá-los de forma adequada, mantendo a interação entre alunos e professores, promovendo a autonomia dos estudantes e, sobretudo, a solidariedade entre eles.

Com o aplicativo MoodleGroups, Lima e Netto (2014, p.6) destacam que é possível identificar essa relação entre os membros e até mesmo em subgrupos aí inseridos.

Assim, com esse dispositivo, o professor com presença pedagógica consegue verificar, através de um sociograma, o nível de interação assinalado em cores diferentes, sendo possível reverter essa situação, intervindo sempre que necessário.

Em se tratando de presença pedagógica, Franco e Lopes corroboram afirmando que:

Com formação adequada, o conhecimento pedagógico dos educadores aliado ao seu desenvolvimento técnico tende a propiciar, por exemplo, o engajamento de estudantes no aprender a investigar e manipular diretamente tecnologias padrão da Internet para produção de conteúdo digital de modo integrado ao desenvolvimento curricular no contexto escolar e fora dele. Estas ações tendem a servir de base para a construção de um processo de educação continuada, mesmo em locais onde os indivíduos vivam em situação sócio-econômica desfavorável, mas tenham acesso aos computadores e às tecnologias de baixo custo fora do ambiente escolar [...] (FRANCO e LOPES, 2005; FRANCO et al, 2006).

A partir do estudo dos autores supracitados também inferimos de forma bastante evidente que a realidade virtual já apresenta resultados concretos nas diversas pesquisas realizadas por instituições que investigam sua aplicabilidade na educação. E essas são responsáveis pelo desenvolvimento de novos aplicativos em ambiente AVA, contribuindo para a qualidade da educação.

Nessa perspectiva, e a fim de enriquecer e dinamizar nossa pesquisa, recorremos ao Banco Internacional de Objetos Educacionais, de onde foram selecionadas algumas atividades para servir aos estudos de caso, com o uso dos aplicativos Zaption e Plickers em audiovisuais e avaliação da aprendizagem, respectivamente. Também recorremos ao YouTube para buscar tutoriais que viabilizassem o planejamento de nossas ações.

Conforme já mencionado, o Moodle foi a plataforma selecionada para a criação de ações referentes às pesquisas. Por conseguinte, consultas à algumas bibliografias estrangeiras também foram feitas, a fim de complementar a pesquisa: "Creating Interactive Lessons in Moodle", "Top 4 Benefits of Using Moodle for your School - Why it Works as a Platform for Student-Teacher Interaction", "4 Reasons Why Teaching Staff Should Not Doubt Moodle", "Increase Student Productivity with Moodle Mobile" e "5 Steps for Student \& Staff to Make the Most of their Moodle".

Finalizando nossas abordagens sobre os pressupostos teóricos, não poderíamos deixar de destacar o Projeto Político Pedagógico (PPP) das instituições de ensino parceiras desta pesquisa, como farol sinalizador de possibilidades para a dinamização de todas as informações e materiais selecionados.

De acordo com os parâmetros apontados pelos Referenciais de Qualidade para a Educação Superior a distância (2007, p.13):

O Material Didático, tanto do ponto de vista da abordagem do conteúdo, quanto da forma, deve estar concebido de acordo com os princípios epistemológicos, metodológicos e políticos explicitados no projeto pedagógico, de modo a facilitar a construção do conhecimento e mediar a interlocução entre estudante e professor, devendo passar por rigoroso processo de avaliação prévia (pré- 
testagem), com o objetivo de identificar necessidades de ajustes, visando o seu aperfeiçoamento. Em consonância com o projeto pedagógico do curso, o material didático, deve desenvolver habilidades e competências específicas, recorrendo a um conjunto de mídias compatível com a proposta e com o contexto socioeconômico do público-alvo.

A partir do excerto acima, também consideramos essas orientações para todos os demais segmentos da Educação, pois se trata de orientação apontada pela LDB, desde 1996.

Por conseguinte, todas as unidades escolares selecionadas para nossas pesquisas precisaram estar alinhadas aos objetivos aqui traçados no que tange ao fomento das práticas de leitura e escrita no contexto do multiletramento digital.

\section{Vivenciando o Ensino Híbrido}

A presente pesquisa foi iniciada no dia 09 de maio de 2016, através de encontro previamente agendado com a direção da instituição parceira, o Instituto de Cultura Técnica (ICT), situado no município de Volta Redonda, Estado do Rio de Janeiro, quando foram apresentadas: a proposta relativa à aplicação de atividade em metodologia de Ensino Híbrido; breve apresentação de textos científicos sobre o assunto; demonstração do funcionamento dos aplicativos propostos para esse trabalho; entrega da Carta de Apresentação e do Termo de Consentimento Livre e Esclarecido, conforme orientações da Coordenação deste curso (PIGEAD/ UFF).

A partir desse primeiro contato, e dadas as características da proposta de pesquisa envolvendo as TDCI, definiu-se que a aplicação da pesquisa seria em Química, já que, segundo a direção, a docente que mais se ajustaria ao perfil demandado lecionava aquela disciplina.

Encontrei certa dificuldade para iniciar os trabalhos de pesquisa, pois precisei aguardar o contato dessa instituição com a confirmação.

No dia 18 de maio de 2016 dei início aos trabalhos, seguindo um cronograma que elaborei para facilitar todo o processo (anexo 1). Nesse dia encontrei-me com a professora indicada, para o devido alinhamento das ações (Fig.1), quando foram escolhidas as 02 turmas do $1^{\circ}$ ano do Ensino Médio que iriam participar da pesquisa: a turma experimental (que aqui será identificada com a letra A) e a turma controle (que será identificada com a letra B). Apresentei também uma breve explanação sobre o Ensino Híbrido e a metodologia - Sala de Aula Invertida - que seria aplicada, reforçando que o mundo moderno requer um docente que promova discussões nas aulas, que estimule o protagonismo dos alunos e que seja o mediador de todo o processo ensinoaprendizagem.

Fig.1: Momento do $1^{\circ}$ encontro com a professora das turmas A e B.

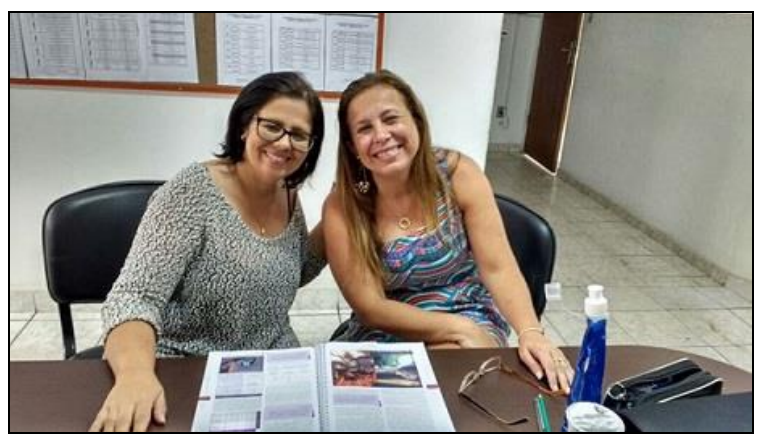


Considero relevante destacar a importância do perfil do professor para a utilização de metodologias híbridas de ensino, sendo fator fundamental a sua formação continuada para uso das tecnologias educacionais.

Nessa perspectiva, não foi difícil implantar o estudo proposto, visto que a docente indicada para me acompanhar em todo o processo, apesar de ainda não conhecer a "Sala de Aula Invertida", dominava perfeitamente as tecnologias necessárias para o uso das Metodologias Ativas, além de ser muito bem quista por seus alunos e antenada às práticas pedagógicas para a educação do século XXI. Tais qualidades são fundamentais para a aplicação dos recursos necessários a essa pesquisa e vêm corroborar o que dizem Lima e Moura (2015, p. 92): “ Talvez a grande dificuldade esteja em romper com séculos de ensino voltado para uma educação vertical, com o professor no topo da relação."

Sendo assim, entendo como uma grata exceção o perfil da professora que encontrei, pois, mesmo não conhecendo todas as ferramentas tecnológicas propostas para a pesquisa, se manteve predisposta em conhecer o novo.

Os professores brasileiros ainda vivem a angústia da adaptação à nova realidade da era digital.

Como afirmam Lima e Moura (2015, p. 90):

Na formação continuada do professor nas escolas brasileiras, tanto públicas quanto particulares, pouco foi desenvolvido em relação às novas habilidades, sobretudo aquelas necessárias para o uso intencional de tecnologias digitais, o que reflete diretamente na continuidade de práticas pedagógicas ultrapassadas, muitas das quais, por sua vez, são reflexo de uma graduação incompatível com o cenário atual das salas de aula [...] Os professores recém-formados são nativos digitais, porém, foram graduados por uma academia experimental em termos de novas tecnologias.

E, em se tratando de tecnologia na escola, pude observar que o material didático ali utilizado oferecia muitos recursos digitais por meio da disponibilidade de endereços eletrônicos com atividades pertinentes aos assuntos da maior parte dos capítulos estudados.

$\mathrm{O}$ assunto definido para a aplicação da pesquisa foi "Modelos Atômicos". Exatamente nesse capítulo não havia oferta de links disponíveis sobre o assunto. Por isso, para uso da ferramenta web Zaption, eu e a professora selecionamos, em comum acordo, um vídeo do YouTube (especificado mais adiante) que mais se adequaria ao perfil dos alunos participantes, favorecendo, assim, um dos objetivos dessa pesquisa: enfatizar a personalização da aprendizagem.

Como afirma MORAN. 2015, p. 35 (apud GOMES, 2013): "Há hoje plataformas adaptativas e aplicativos que orientam os professores sobre como cada aluno aprende, em que estágio se encontra e o que o motiva mais."

O Zaption se ajusta perfeitamente ao que este autor nos diz, já que possui uma plataforma própria, onde podemos inserir o vídeo desejado como lições interativas com momentos onde iremos inserir enquetes, imagens, textos, perguntas de múltipla escolha e discussões.

No dia 22 de maio de 2016 procedi a um novo encontro com a professora para a realização dos últimos alinhamentos, como a seleção das perguntas para o quiz do Plickers e análise final do material elaborado para o Zaption.

No dia 23 de maio de 2016, em encontro com a equipe pedagógica da escola, juntamente com a professora parceira, apresentei a mídia selecionada já implantada no aplicativo Zaption (utilizado com foco na instrução) para que a validação pudesse ser feita, bem como o material específico do aplicativo Plickers (utilizado com foco na avaliação) que consiste em um conjunto de cartões-resposta (Fig.2) que podem ser escaneados pela câmera de qualquer smarthphone (desde de que o aparelho tenha realizado o download deste aplicativo) e uma plataforma específica para 
verificar no computador e (ou) no próprio aparelho móvel junto aos alunos, em tempo real, o número de possíveis acertos e erros.

Sugeri à equipe pedagógica que analisasse com atenção o material produzido a fim de constatar sua versatilidade e qualidade desejadas. (Fig.3)

Fig.2: Cartões-resposta utilizados no aplicativo Plickers.

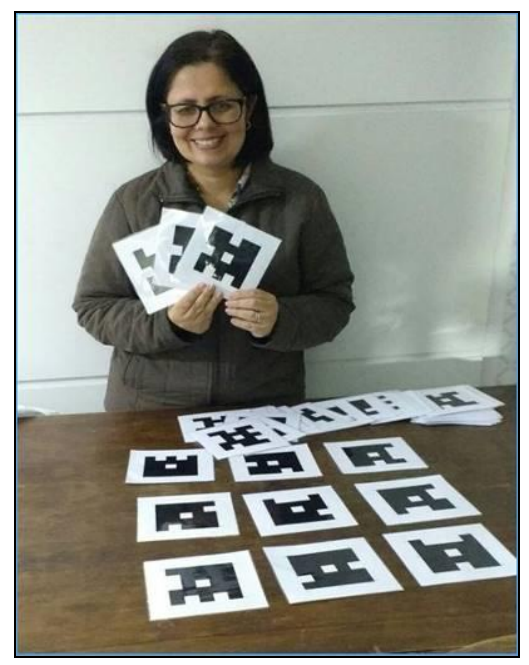

Fig.3: Momento do encontro com a equipe pedagógica para análise e validação dos aplicativos utilizados nesta pesquisa.

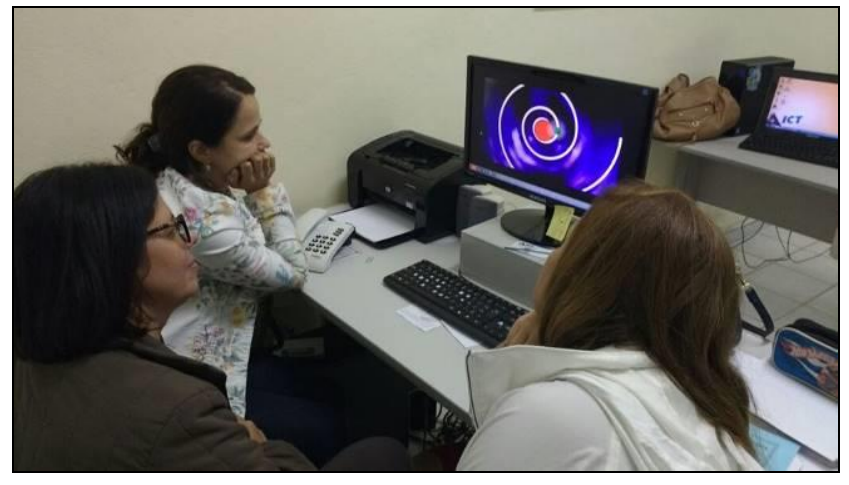

No dia 03 de junho de 2016, logo após a finalização das ações pedagógicas desta pesquisa vinculadas ao ICT, participei do III Seminário de Educação: Inovação e Criatividade em debate Gestão do Conhecimento da Cultura Digital (Fig.4), promovido pela Escola Técnica Pandiá Calógeras (ETPC) em Volta Redonda - RJ, com a presença do Prof. Dr. Lino de Macedo (USP) e da Prof ${ }^{a}$ Dr $^{\mathrm{a}}$ Dênia Falcão de Bittencourt (IPE - Inova Práticas Educacionais/ Santa Catarina - RS), quando novamente pude confirmar que há uma forte tendência mundial para o uso do Ensino Híbrido e que no Brasil muitas pesquisas se despontam com o propósito de fortalecer esse campo educacional. 
Fig.4: III Seminário de Educação promovido pela ETPC

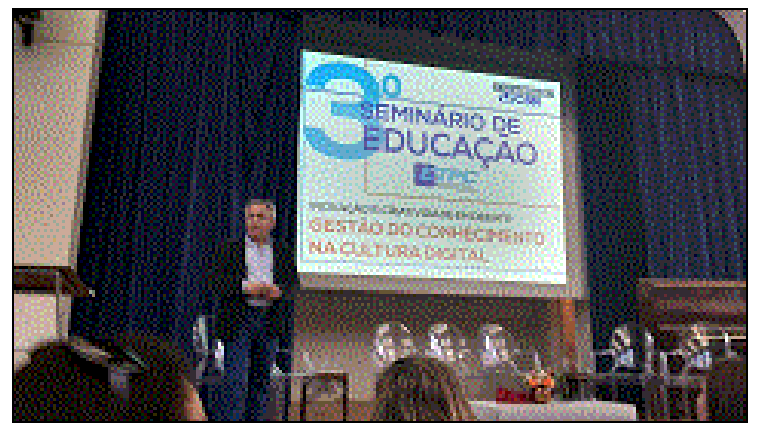

Assuntos como: "Gestão da aprendizagem colaborativa"; "Cultura digital"; "Sala de Aula Invertida"; "Aprendizagem por Pares"; "Web 3.0", entre outros, foram muito abordados, o que reforça, no meu ponto de vista, que, ao longo dessa pesquisa, eu estive no caminho correto.

\subsection{Detalhamentos da elaboração do material da pesquisa}

\subsubsection{Zaption}

O Zaption é um aplicativo para inserção de vídeos. Mas, além disso, possui plataforma adaptativa com produção de gráficos e relatórios individualizados, favorecendo, assim, a personalização da aprendizagem.

Nesse sentido, o vídeo selecionado do YouTube foi o "Tudo se Transforma, História da Química, História dos Modelos Atômicos", disponível em: http://www.youtube.com/watch?v=58xkET9F7MY.

$\mathrm{Na}$ plataforma do Zaption foram implantadas 07 perguntas: 4 de múltipla escolha e 3 abertas, para serem visualizadas ao longo da apresentação do vídeo (Tabela 1). Além destas, ao final, apresentei a letra da música "Estrutura Atômica" como atividade para pontuação extra e que não foi computada para fins dessa pesquisa (anexo 2).

Após elaborado, no dia 24 de maio de 2016, às 7h30, o material foi disponibilizado previamente para os alunos por meio de um link. Estipulou-se o prazo de 11 horas para que pudessem acessá-lo em seus computadores domésticos, laboratório de informática da escola ou aparelhos móveis (smarthphones, tablets, Lan House etc.), configurando, assim, uma das características da Sala de Aula Invertida que é a disponibilidade de material para ser explorado fora da sala de aula.

Ao longo do dia, através de meu computador, acessei a plataforma do Zaption e realizei o monitoramento da participação dos alunos, cuja análise dos resultados se encontra mais adiante. 
Tabela 1: Questionário elaborado para a plataforma adaptativa do aplicativo Zaption, utilizado ao longo do vídeo proposto.

\begin{tabular}{|c|c|c|}
\hline TIPO & PERGUNTA & RESPOSTA \\
\hline $\begin{array}{l}\text { RESPOSTA } \\
\text { ABERTA }\end{array}$ & E aí? Você já sabe o assunto da aula de hoje? Qual é? & . \\
\hline $\begin{array}{l}\text { RESPOSTA } \\
\text { ABERTA }\end{array}$ & $\begin{array}{l}\text { Qual é a origem da palavra "átomo"? A dica está em: } \\
\text { http://www.klickeducacao.com.br/conteudo/pagina/0,6313,POR- } \\
\text { 4611-37442-,00.html }\end{array}$ & \\
\hline $\begin{array}{l}\text { MÚLTIPLA } \\
\text { ESCOLHA }\end{array}$ & $\begin{array}{l}\text { Qual é o valor da carga dos elétrons? } \\
\qquad \begin{aligned} \text { A. } & \text { POSITIVA } \\
\text { B. } & \text { NEGATIVA }\end{aligned}\end{array}$ & \\
\hline $\begin{array}{l}\text { RESPOSTA } \\
\text { ABERTA }\end{array}$ & $\begin{array}{l}\text { Explique com suas palavras a diferença entre os modelos } \\
\text { atômicos de Dalton e Thomson? }\end{array}$ & \\
\hline $\begin{array}{l}\text { RESPOSTA } \\
\text { ABERTA }\end{array}$ & $\begin{array}{l}\text { Explique com suas palavras o modelo atômico criado por } \\
\text { Rutherford? }\end{array}$ & \\
\hline $\begin{array}{l}\text { MÚLTIPLA } \\
\text { ESCOLHA }\end{array}$ & $\begin{array}{l}\text { Qual é o valor da carga do núcleo de um átomo? } \\
\qquad \begin{array}{l}\text { A. POSITIVA } \\
\text { B. NEGATIVA }\end{array}\end{array}$ & . \\
\hline
\end{tabular}

Fonte: https://www.zaption.com

Após análise das respostas registradas na plataforma do Zaption, para a aula seguinte, orientei a professora a elaborar uma atividade em sala de aula a fim de verificar in locus o que, de fato, os alunos haviam apreendido a partir da atividade que realizaram fora do ambiente escolar.

Assim, no dia 25 de maio de 2016, propusemos uma atividade em duplas, onde os alunos teriam 5 minutos para escrever tudo que lembrassem a respeito de cada uma das 5 palavras $^{1}$ que seriam apresentadas (brain storming), perfazendo, portanto, 25 minutos ao final (Fig.5).

Esta atividade balizou a presente pesquisa, pois também foi proposta em formato de duplas aos alunos da turma B (turma controle) que, para o desenvolvimento dos mesmos conteúdos (Modelos Atômicos) apenas vivenciaram as explicações orais da professora (lousa branca) e as atividades do livro didático (Fig.5).

Fig.5: Alunos da turma A (turma experimental) e da turma B (turma controle) realizando a atividade proposta em pares (Peer Instruction) em momentos distintos:
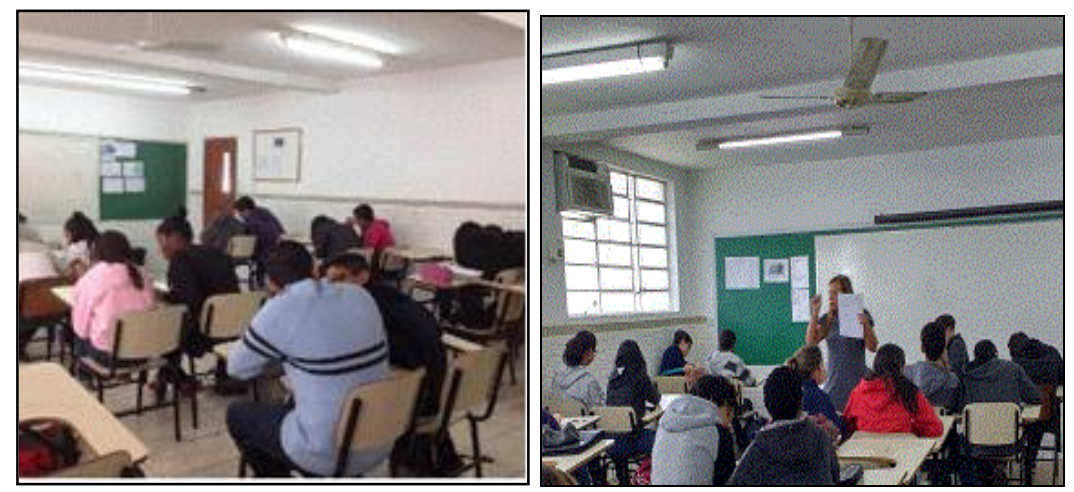

\footnotetext{
${ }^{1}$ As palavras da atividade em pares (Peer Instruction) foram: "átomo", "prótons e elétrons", "Rutherford", "Bohr" e "Modelos Atômicos".
} 
Atividades em pares (Peer Instructions) favorecem a aprendizagem e reforçam as explicações anteriormente vistas. Podem ser realizadas em duplas ou em grupos maiores (times).

Mazur (2015, p. 12) afirma:

A melhoria observada na confiança também não surpreende. Os estudantes que inicialmente estão corretos, mas não muito confiantes, tornam-se mais confiantes quando verificam que seus colegas escolheram a mesma resposta ou quando sua confiança é reforçada ao construírem um raciocínio que conduz à resposta correta.

A seguir as folhas foram recolhidas para Feedback (Fig.6), pois desejávamos comparar o nível de compreensão dos conceitos trabalhados em ambas as turmas.

Fig.6: Momento de análise (Feedback) das atividades presenciais realizadas em pares.

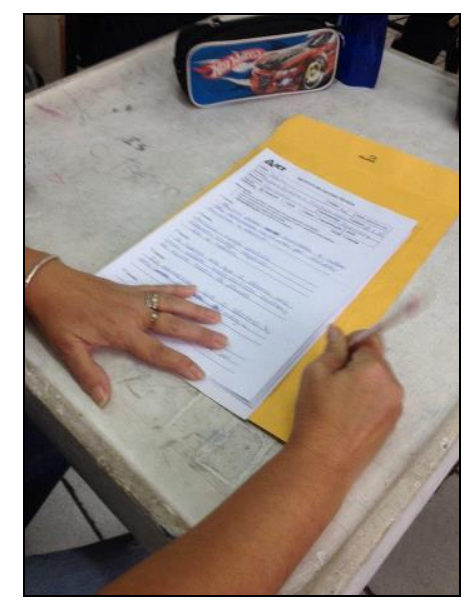

No dia 30 de maio de 2016, aos alunos da turma A foram oportunizadas novas atividades em grupos maiores (Fig.7), organizados por "times" compostos por 4 alunos em diferentes níveis de desempenho, conforme os resultados obtidos na vídeo-aula e nas atividades em duplas, favorecendo, assim, a aprendizagem colaborativa por meio de sua personalização.

Fig.7: Momentos das atividades em "times":

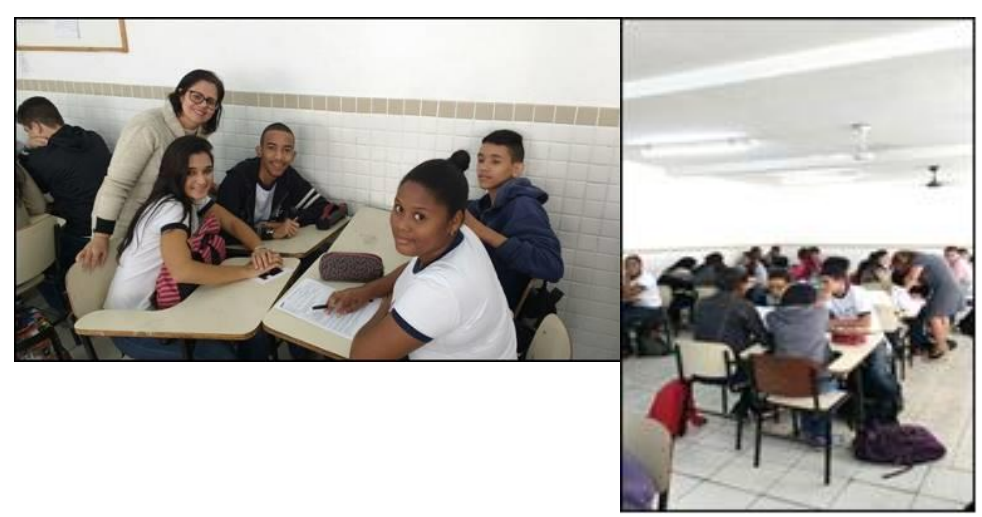




\subsubsection{Plickers}

Já o aplicativo Plickers foi utilizado para a avaliação final de toda a aprendizagem.

Lembrando que este aplicativos, além de oferecer a correção automática das respostas dadas pelos alunos, também disponibiliza uma plataforma para que o professor analise os gráficos gerados pelos resultados, oportunizando aos alunos envolvidos uma certa autonomia no momento em que vão responder, já que precisam levantar os cartões de forma individual e simultânea (Fig.8).

Fig.8: Momento em que os alunos participaram da atividade avaliativa com uso do aplicativo Plickers.

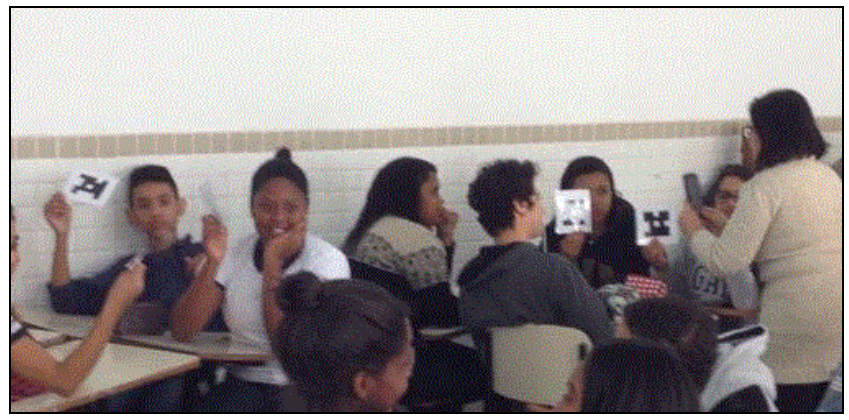

\subsection{Análise dos dados}

A análise foi feita, primeiramente, entre os dias 21 e 29 de maio de 2016, observando-se o número de acessos por dia (Gráfico 1). Identificou-se um excelente nível de participação, denotando a motivação da turma em realizar a atividade proposta. A partir dos demais gráficos disponibilizados pelo aplicativo Zaption, identificou-se o nível de desempenho de cada aluno participante (Gráfico 2), facilitando, assim, a formação dos grupos para a próxima atividade em sala de aula.

Gráfico 1: Número de visitantes por data

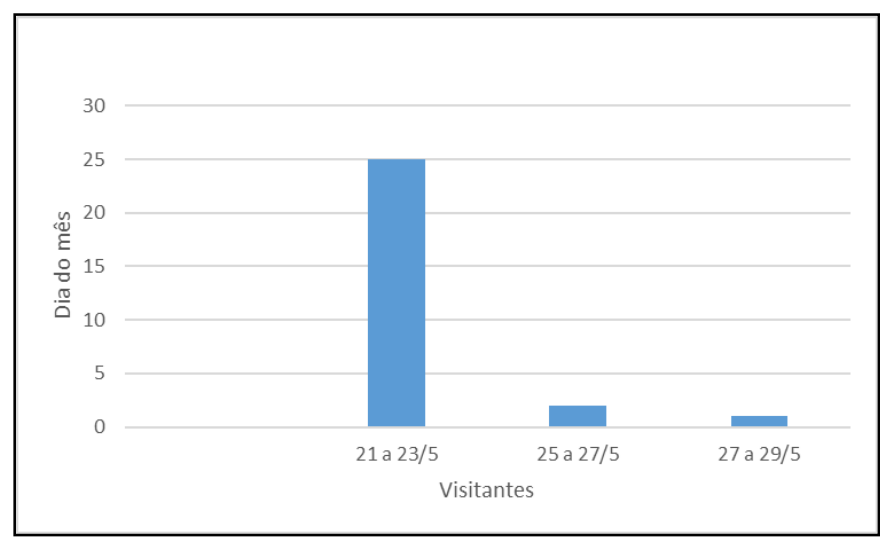

Fonte: Zaption 
Com relação ao nível de apreensão dos conceitos desenvolvidos na vídeo-aula, dos 28 participantes: 10 alunos (36\%) apresentaram grau avançado; 14 alunos (50 \%) encontravam-se em nível intermediário e 4 alunos (14\%) encontravam-se em fase de construção dessa aprendizagem (Gráfico 2).

Gráfico 2: Desempenho da Turma A

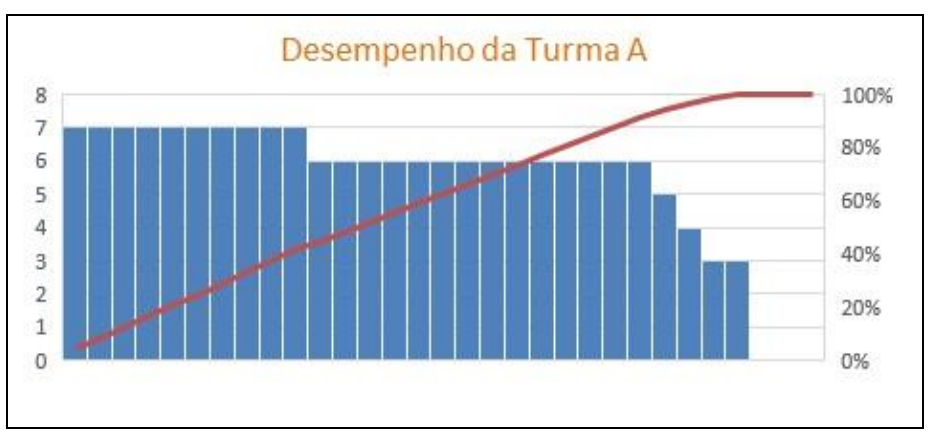

Fonte: Excel

A partir da análise dos Gráficos 1 e 2, observa-se que, dos 42 alunos da turma A, 28 acessaram a vídeo-aula, ou seja, $65 \%$ da turma (Gráfico 3).

Gráfico 3: Participação da turma A na atividade Zaption

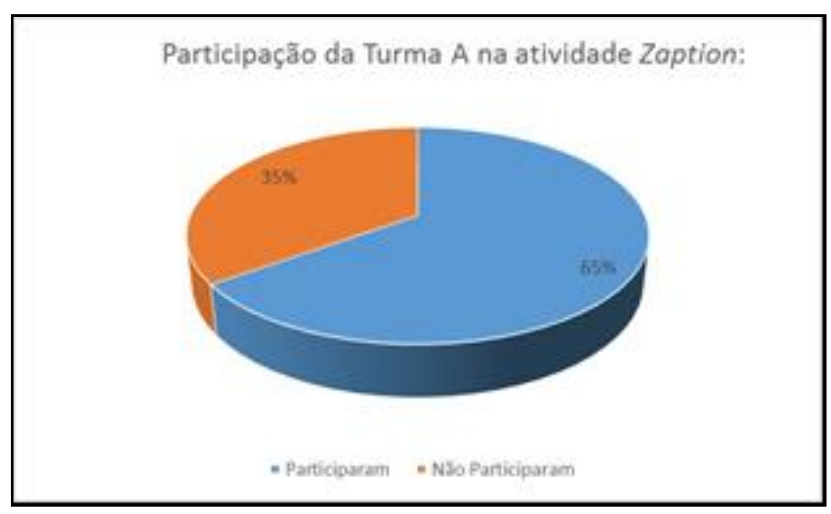

Fonte: Zaption

Por meio da pergunta "Por que você não participou da vídeo-aula?", os 14 alunos (35\%) apresentaram as seguintes respostas, por ordem de relevância

1. Problemas de ordem técnica no computador utilizado.

2. Não possuir computador. 
3. Não conseguir acesso pelo celular.

$\mathrm{Na}$ atividade do Plickers, observou-se um melhor desempenho se comparado ao da atividade em duplas. Notou-se também que os alunos que não participaram das atividades anteriores de forma parcial, ou total, foram os que mais erros apresentaram nesta atividade.

Gráfico 4: Gráfico de desempenho da atividade do Plickers:

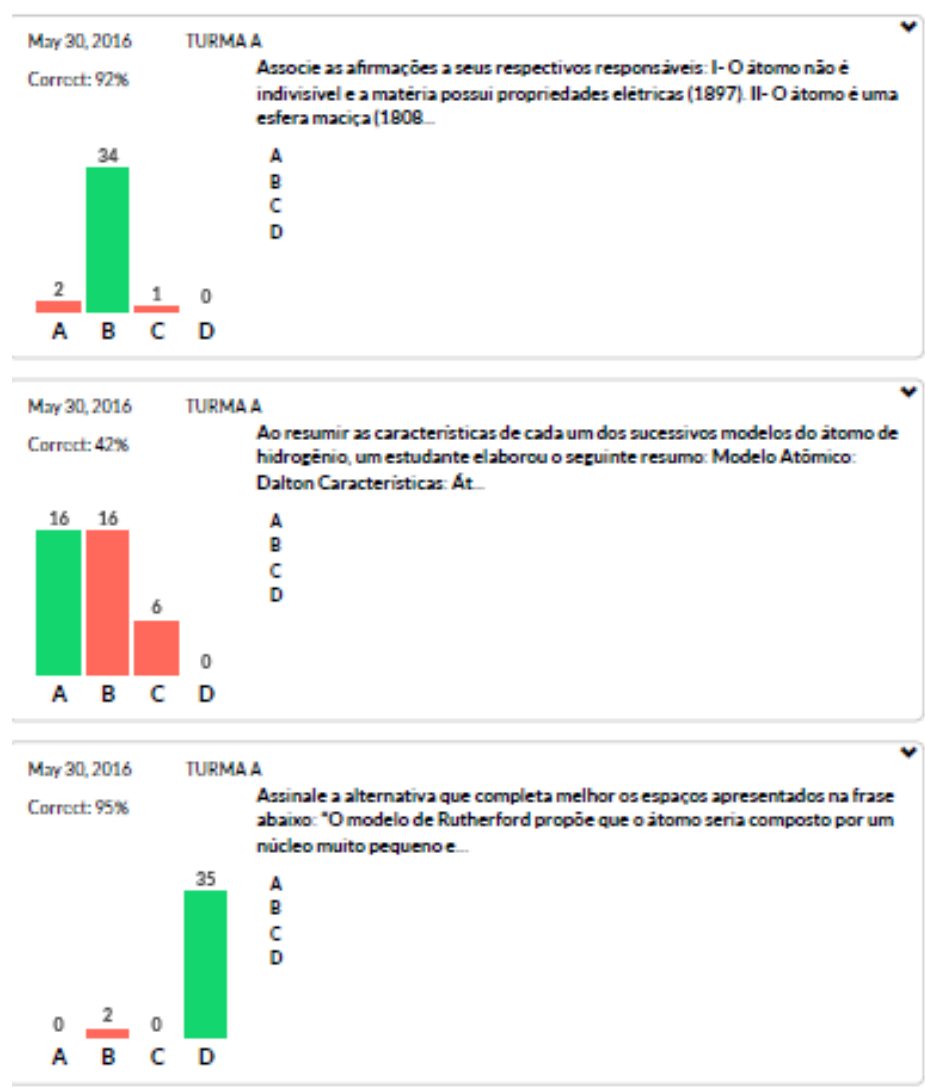

\subsubsection{Análise comparativa dos resultados gerais de desempenho entre as turmas A e B}

Com relação aos 42 alunos da turma $\mathrm{A}$, apesar de inicialmente não terem todos participado na íntegra de todas as atividades propostas, ao longo de todo o processo em que, estrategicamente, novas oportunidades de construção da aprendizagem foram ofertadas (trabalhos em duplas e times), os resultados foram bastante significativos. Como se pode observar, em geral, a turma que usou os aplicativos obteve melhor desempenho (gráfico 5 e gráfico 6). 
Gráfico 5: Gráfico comparativo Zaption

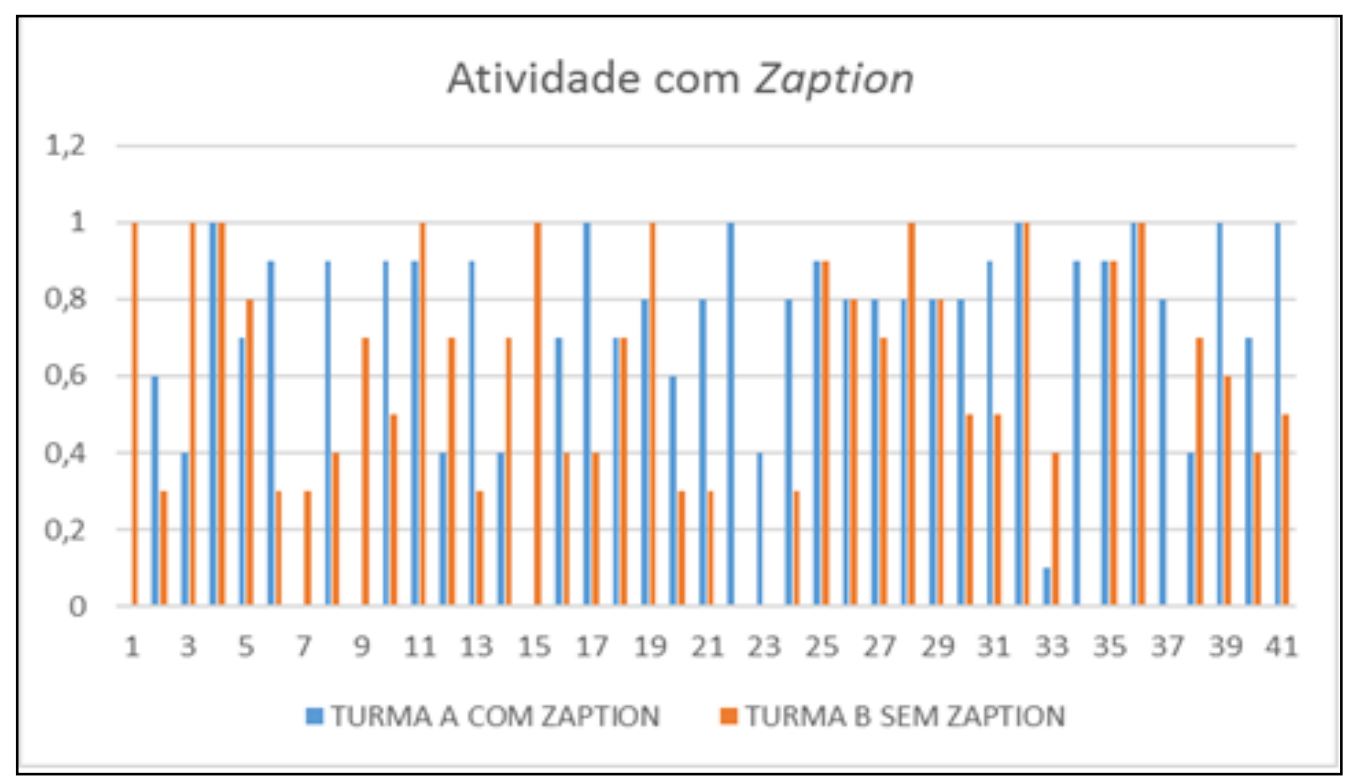

Gráfico 6: Gráfico comparativo Plickers

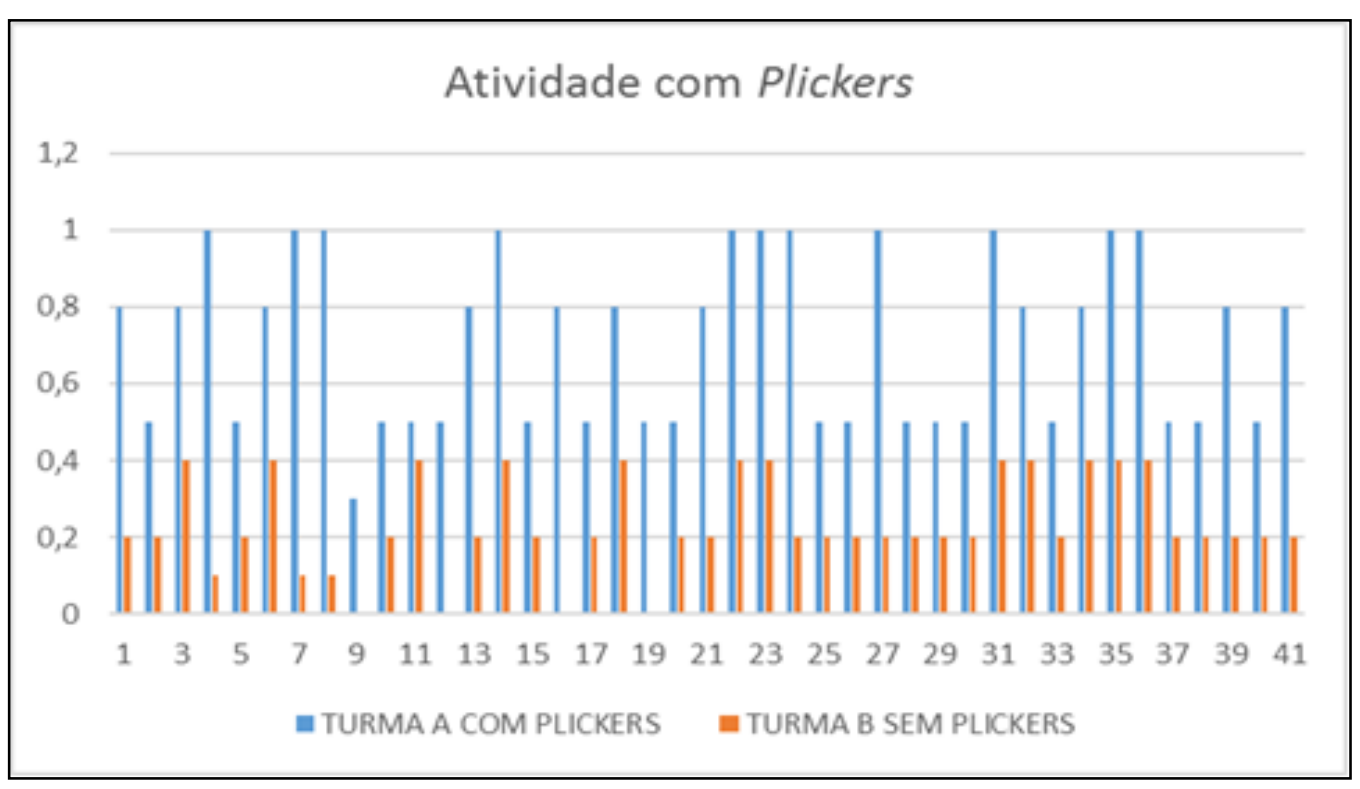




\section{Considerações finais}

Ao longo dessa pesquisa observei que as metodologias de Ensino Híbrido ainda consistem em algo novo para muitos professores. Por outro lado, alguns as vêm utilizando de modo parcial e/ou empírica, mas sem relação direta, ou na íntegra, com os princípios fundamentais das Metodologias Ativas, que são: a personalização do ensino; o professor mediador; o aluno protagonista; o binômio tempo-espaço possibilitado pelo uso dos recursos tecnológicos e, por conseguinte, a cultura escolar voltada para esses fins, a qual se exige esteja imersa nessa dinâmica.

Tais aspectos acima destacados foram recorrentes em todos os trabalhos realizados por nosso grupo de pesquisa e, portanto, em todos os segmentos educativos abordados (Ensino Fundamental II, Ensino Médio e Ensino Superior). Através dos resultados estatísticos extraídos da plataforma Google e dos aplicativos utilizados (Zaption, Plickers, Google Forms, Flubaroo) em plataformas adaptativas com uso de Metologias Ativas, comprovou-se que, no modelo de Ensino Híbrido, a tecnologia favorece o enriquecimento na oferta de materiais de estudo variados, bem como viabiliza, de fato, os processos avaliativos por meio de recursos diversos, como os sistemas de cooperação e os registros individuais de resultados.

Além desses aspectos, percebi que a qualidade das relações interpessoais dos professores com seus alunos também é um fator fundamental para o sucesso da aprendizagem, independentemente desta estar associada ao ensino tradicional, ou às metodologias ativas.

Em contrapartida, os processos avaliativos interpretados apenas como fim e não como meio, ainda são comuns, gerando resistências e incertezas, tanto para o professor, quanto para o aluno, como apontado nos gráficos de resultados da turma B (turma controle) da pesquisa que realizei. Ao se deparar com novas possibilidades avaliativas a partir de recursos digitais, os participantes dessa pesquisa demonstraram grande interesse em aprender a usá-los. Mas vale enfatizar que tais ações sem os cuidados e intenções corretas podem gerar brechas para uma possível banalização quanto à forma de aplicação das metodologias híbridas na aprendizagem.

Durante o tempo que convivi com a comunidade escolar onde realizei essa pesquisa, pude perceber, em momentos de conversas informais com outros professores, certo interesse por parte destes em querer conhecer melhor os processos vinculados às Metodologias Ativas. Mas só isso não bastaria para que aquela instituição (como qualquer outra) pudesse implantar a proposta aqui pesquisada, pois, além da boa formação do professor, também as seguintes adequações: curricular e de infraestrutura da escola; das atividades curriculares e da dinâmica da sala de aula, devem ser requisitos fundamentais.

Nesse sentido, o planejamento, a elaboração prévia e cuidadosa de material específico e o ajuste das ferramentas digitais às reais possibilidades da clientela foco são pontos que carecem de total atenção por parte do corpo docente e da equipe pedagógica, como apontada na pesquisa realizada com a utilização do Moodle, onde a pouca utilização dos recursos ofertados por essa plataforma foi evidenciada. Também na utilização do Zaption que limita o número de usuários se usado na versão gratuita.

Portanto, promover a personalização da aprendizagem aliada ao uso das tecnologias, tendo o professor cheio de entusiasmo para aprender e ensinar, consciente de que não é o único detentor do conhecimento no processo de ensino e aprendizagem é um sonho possível de ser realizado, conforme afirma Ana Maria Diniz (BACICH; NETO; TREVISANI, 2015, p. 19), presidente do conselho do Instituto Península: "Quando isso acontecer, o Brasil será de fato um país diferente. 
Somente nesse dia estaremos no caminho seguro para extinguir a principal barreira que nos separa dos países ricos: a barreira do conhecimento".

O fator "humano" continua sendo o elo entre a máquina e o aluno e, nesse sentido, devemos estar preparados para um mundo cada vez mais global e dinâmico. Por isso, nós os imigrantes digitais, precisamos estar imersos em modo "full time" se quisermos, enquanto educadores, acompanhar os interesses dessa geração que desponta.

Considerada como geração Alpha, em termos de estímulos educativos, esta exigirá muito mais, conforme afirma Fernanda Fúria, Mestre em Psicologia de crianças e adolescentes, pela University College London (FÚRIA, 2015, p. 12 e13):

\begin{abstract}
A geração Alpha nasceu em um contexto global no qual as novas tecnologias estão bem mais desenvolvidas do que há 10 anos. [...] terão, provavelmente, o maior nível educacional de todas as gerações [...] serão as primeiras a experimentar um novo sistema escolar, mais personalizado e híbrido (on-line e off-line), com foco na autonomia do aluno e no aprendizado baseado em projetos para aprender por meio de situações do cotidiano; e vão deter o maior conhecimento tecnológico da história. [...]. Tudo isso vai impactar a maneira de a geração Alpha consumir produtos e informação. Além de se refletir na forma como as pessoas se relacionarão entre elas e com as coisas. Avalia Fernanda Fúria.
\end{abstract}

Ante todo o acima exposto e após meticulosa pesquisa levada a termo, depreende-se que diante de tantas inovações, o professor ainda é a melhor tecnologia e permanece como elemento fundamental no processo ensino-aprendizagem. Por isso a importância de sua permanente formação. O Ensino Híbrido veio para ficar e se expandir.

Nessa perspectiva, necessário ainda se faz que haja, no campo das pesquisas, novas formas de incentivo para aplicação do Ensino Híbrido, em especial no Brasil, pois, através desse trabalho, denotou-se que ainda há carências em aspectos vinculados à cultura digital na Educação, o que pode ser viabilizado por meio de processos formativos que qualifiquem os docentes e os potencializem com insumos para melhores apropriações pedagógicas e, por conseguinte, para um uso e adequação mais consistentes das ferramentas digitais de aprendizagem disponíveis e acessíveis em nosso país. 


\section{Referências}

ALVES, Lucineia. Revista Brasileira de Aprendizagem Aberta e a Distância (ABED). Disponível em: <www.abed.org.br/revistacientifica/Revista_PDF_Doc/.../Artigo_07.pdf>. Acesso em: 20/02/2016.

AUDACITY. Disponível em: <http://www.audacityteam.org>. Acesso em: 25/03/16.

BACICH, Lilian; NETO, Adolfo Tanzi; TREVISANI, Fernando de Mello. Ensino Híbrido: Personalização da tecnologia na educação. Porto Alegre: Penso, 2015. 270 p. Cap. 1. 35.

BOOK CREATOR. Disponível em: <https://itunes.apple.com/us/app/book-creator-for-ipadcreate/id442378070?mt=8>. Acesso em: 25/03/16.

BRASIL. Lei de Diretrizes e Bases da Educação: Lei no 9.394/96 - 24 de dez. 1996. Estabelece as diretrizes e bases da educação nacional. Brasília, 1998. Disponível em: <http://portal.mec.gov.br/component/content/article?id=12907:legislacoes>. Acesso em: 25/03/2016.

CAMALEO. Disponível em: <https://pt.calameo.com/>. Acesso em: 25/03/16.

CAMTASIA. Disponível em: <https://www.techsmith.com/camtasia.html>. Acesso em: 25/03/16.

COURSERA. Disponível em: <https://www.coursera.org/>. Acesso em: 25/03/16.

CREATING INTERACTIVE LESSONS IN MOODLE. Disponível em: <http://stellarlearning.ca/2016/01/08/creating-interactive-lessons-in-moodle/>. Acesso em: $25 / 03 / 16$

CHRISTENSEN, Clayton; HORN, Michael. Inovação na Sala de Aula: Como a Inovação Disruptiva Muda a Forma de Aprender. Porto Alegre: Bookman, 2012.

DELORS, Jean Jacques et al. Educação: um tesouro a descobrir. Tradução de José Carlos Eufrázio. São Paulo: Cortez, 2002.

COSTA, Luciano Andreatta Carvalho; FRANCO, Sérgio Roberto Kieling. Ambientes Virtuais de Aprendizagem e suas Possibilidades Construtivistas. In: Novas Tecnologias da Educação, V.3, $\mathrm{n}^{\mathrm{O}}$ 1, Maio, 2005. UFRGS. Porto Alegre -RS. Disponível em: <http://www.ufrgs.br/nucleoead/documentos/costaAmbientes.pdf>. Acesso em: 16/03/2016.

DANTAS, Tiago. "Youtube"; Brasil Escola. Disponível em <http://brasilescola.uol.com.br/informatica/youtube.htm>. Acesso em: 02/04/2016.

EDMODO. Disponível em: <https://www.edmodo.com/?language=ptbr\&auto_selected_lang=true\&logout=true\&user_type=intl $>$. Acesso em: 25/03/16.

EDX. Disponível em: 〈https://www.edx.org>. Acesso em: 25/03/16. 
FRANCO, Jorge Ferreira et al. Experiências de Uso de Mídias Interativas como Suporte para Autoria e Construção Colaborativa do Conhecimento. 2007. Disponível em: <http://www.cinted.ufrgs.br/ciclo9/artigos/2cJorge.pdf>. Acesso em: 15/10/2015.

FÚRIA, Fernanda. Geração Alpha e o futuro da educação. Revista Tutores. 2014. Disponível em: $\quad\langle$ http://revistatutores.editoralamonica.com.br/pub/lamonica/index13/?true?\&edicao=2973>. Acesso em: 04/06/2016.

GOOGLE APRESENTAÇÕES. Disponível em: <https://www.google.com/intl/ptBR/slides/about/>. Acesso em: 25/03/16.

KHAN, Salmon. Khan Academy. Fundação Lemann. São Paulo, 2016. Disponível em: <http://www.fundacaolemann.org.br/khan-academy>. Acesso em: 21/02/2016.

LIMA, Dhanielly; GADELHA, Bruno; NETTO, José Francisco e BREMGARTNER, Vitor. MoodleGroups: Um Aplicativo para Identificar as Relações Sociais entre Alunos em Ambientes Virtuais de Aprendizagem. In: SBSC 2014 Proceedings - Ongoing Research. Curitiba-PR 2014. Disponível em: <https://www.researchgate.net/profile/Dhanielly_Lima/publication/266736366_MoodleGroups_U m_Aplicativo_para_Identificar_as_Relaes_Sociais_entre_Alunos_em_Ambientes_Virtuais_de_Apr endizagem/links/543984a00cf204cab1d9662d.pdf>. Acesso em: 26/03/2016.

LIMA, Leandro H. Fernandes; MOURA, Flávia Ribeiro. O professor no Ensino Híbrido. In: BACICH, Lilian; NETO, Adolfo Tanzi; TREVISANI, Fernando de Mello. Ensino Híbrido: Personalização da tecnologia na educação. Porto Alegre: Penso, 2015. 270 p. Cap. 4.90

LUCIO, Carlos Frederico. Uso de Aplicativos para Avaliações, Feedbacks e Exercícios. In: Fórum Metodologias Ativas 2015 (PUC-SP), 25. 2015, São Paulo. Anais do Fórum Metodologias Ativas 2015. São Paulo: ESPM, 2015. Artigos, p. 24. Disponível em: $\langle$ http://www.pucsp.br/sites/default/files/download/anais_forum_metodologias_ativas_2015.pdf >. Acesso em: 26/03/2016.

MARTINHO, Tânia; POMBO, Lúcia. Potencialidades das TIC no ensino das Ciências Naturais - um estudo de caso. In: Revista Electrónica de Enseñanza de las Ciencias. Vol.8, N², $2009 . \quad$ Disponível <http://www.saum.uvigo.es/reec/volumenes/volumen8/ART8_Vol8_N2.pdf>. Acesso em: $17 / 02 / 2016$.

MATHIAS, Sergio Larruscaim; AKAI, Celio Sakai. Utilização da Ferramenta Google Forms no Processo de Avaliação Institucional: Estudo de Caso nas Faculdades Magsul. Faculdades Magsul, 2013, $\quad$ p. $\quad 7 \quad$ a $12 . \quad$ Disponível em: <http://download.inep.gov.br/educacao_superior/avaliacao_institucional/seminarios_regionais/tra balhos_regiao/2013/centro_oeste/eixo_1/google_forms_processo_avaliacao_instit_estudo caso_faculdades_mag.pdf. Acesso em: 09/04/2016.

MAZUR, Eric. Peer instruction: a revolução da aprendizagem ativa. Porto Alegre: Penso, 2015.

MELLO, Suely Amaral. Infância e humanização: algumas considerações na perspectiva histórico cultural. Perspectiva. Revista do Centro de Educação da Universidade Federal de Santa Catarina. V. 25, n. 1. jan/jun, 2007. 
MENDES, Gilnei. Proposta de uma Unidade de Ensino Potencialmente Significativa para Subsidiar o Estudo de Geometria Analítica Auxiliada pelo Software Geogebra. Universidade Severino Sombra, 2015, p.79. Disponível em: <http://www.uss.br/arquivos/posgraduacao/strictosensu/educacaoMatematica/dissertacoes/2015/Di ssertacao_Gilnei_Mendes.pdf $>$. Acesso em: 09/04/2016.

MORAN, José. Educação Híbrida. Um conceito-chave para a educação, hoje. In: BACICH, Lilian; NETO, Adolfo Tanzi; TREVISANI, Fernando de Mello. Ensino Híbrido: Personalização da tecnologia na educação. Porto Alegre: Penso, 2015. 270 p. Cap. 1. 35.

REFERENCIAIS DE QUALIDADE PARA EDUCAÇÃO SUPERIOR A DISTÂNCIA. Disponível em: <http://portal.mec.gov.br/seed/arquivos/pdf/legislacao/refead1.pdf〉. Acesso em: 09/04/2016.

ROSA, Paulo Ricardo da Silva. O uso de Recursos Audiovisuais e o Ensino de Ciências. In: CADERNO BRASILEIRO DO ENSINO DE FÍSICA. Cad.Cat.Ens.Fís., v. 17, n. 1: p. 33-49, abr. 2000. Disponível em: <https://periodicos.ufsc.br/index.php/fisica/article/view/6784/6249>. Acesso em: 17/02/2016.

SCHNEIDER, Fernanda. In: BACICH, Lilian; NETO, Adolfo Tanzi; TREVISANI, Fernando de Mello. Ensino Híbrido: Personalização da tecnologia na educação. Porto Alegre: Penso, 2015. 270 p. Cap. 9. 169-171.

SILVA, Rodrigo Abrantes; CAMARGO, Ailton Luiz. In: BACICH, Lilian; NETO, Adolfo Tanzi; Ensino Híbrido: Personalização da tecnologia na educação. Porto Alegre: Penso, 2015.

SOBREIRA, Lúcia Helena Rodrigues; BORRALHO, António Manuel Águas e OLIVEIRA, Vítor José Martins. Vivências de alunos e professores no uso da plataforma moodle como complemento às aulas presenciais de química para $01^{\circ}$ ano do ensino médio: um estudo de caso. 2013. Disponível em: $<$ http://www.latec.ufrj.br/revistas/index.php?journal=educaonline \&page=article\&op=view\&path\% 5B\%5D=521\&path\%5B\%5D=588>. Acesso em: 26/03/2016.

STAKER, Heather; HORN, Michael. Classifying K-12 blended learning. Mountain View, CA: Innosight Institute, Inc. 2012. Disponível em: <http://www.christenseninstitute.org/wpcontent/uploads/2013/04/Classifying-K-12-blended-learning.pdf>. Acesso em: 02/04/2016.

TREVISANI, Fernando de Mello. Ensino Híbrido: Personalização da tecnologia na educação. Porto Alegre: Penso, 2015.

TRINDADE, Jorge A.; FIOLHAIS, Carlos. A realidade virtual no ensino e aprendizagem da Física e da Química. V.19, Fasc. 2, 1996. Gazeta de Física. In: Sociedade Portuguesa de Física. Disponível em: <http://nautilus.fis.uc.pt/personal/jtrindade/ jtrindade/pub/6.pdf>. Acesso em: 26/03/2016.

VALENTE, José Armando. Blended learning e as mudanças no ensino superior: a proposta da sala de aula invertida. Educar em Revista, Curitiba -PR, Edição Especial no 4/2014, p. 79-97. Editora UFPR. Disponível em: <http://www.scielo.br/pdf/er/nspe4/0101-4358-er-esp-0400079.pdf>. Acesso em: 17/02/2016. 
WIKIVERSIDADE. Ambientes Virtuais de Aprendizagem/Avaliação Colaborativa. 2012. Disponível

<https://pt.wikiversity.org/wiki/Ambientes_Virtuais_de_Aprendizagem/Avalia\%C3\%A7\%C3\%A3 o_colaborativa >. Acesso em: 26/03/2016. 


\section{Anexos:}

Anexo 1: Cronograma de Ações referentes ao Estudo de Caso

CURSO V PÓS-GRADUAÇÃO: PLANEJAMENTO, IMPLEMENTAÇÃO E GESTÃO DA
EDUCAÇÃO A DISTÂNCIA (PIGEAD/ UFF)

NOME DA INSTITUIÇÃO PARCEIRA: INSTITUTO DE CULTURA TÉCNICA

\begin{tabular}{|c|c|c|c|c|c|}
\hline & \multicolumn{5}{|c|}{ ENSINO MÉDIO ARTICULADO - ELETROTÉCNICA } \\
\hline ANO: & TURMAS: & PERÍODO: & \multicolumn{3}{|c|}{ DISCIPLINA / PROPOSTA METODOLÓGICA } \\
\hline 2016 & $\begin{array}{l}\text { TURMA A e } \\
\text { TURMA B }\end{array}$ & $\begin{array}{l}\text { 09/05/2016 à } \\
31 / 05 / 2016\end{array}$ & \multicolumn{3}{|c|}{$\begin{array}{l}\text { QUÍMICA/ ENSINO HÍBRIDO (SALA DE AULA } \\
\text { INVERTIDA) }\end{array}$} \\
\hline \multicolumn{2}{|c|}{ MOMENTOS } & ESTRATÉGIAS & RECURSOS & INDICADORES & FOCO \\
\hline \multicolumn{2}{|c|}{$\begin{array}{l}\text { 1. Solicitação de } \\
\text { autorização para a } \\
\text { aplicação da pesquisa junto } \\
\text { à Direção da unidade } \\
\text { escolar onde a pesquisa } \\
\text { será realizada. } 09 / 5\end{array}$} & Ligação telefônica & Telefone & $\begin{array}{l}\text { Retorno da } \\
\text { Secretária da } \\
\text { escola }\end{array}$ & $\begin{array}{l}\text { Aplicação da } \\
\text { pesquisa na } \\
\text { instituição } \\
\text { selecionada. }\end{array}$ \\
\hline \multicolumn{2}{|c|}{$\begin{array}{l}\text { 2. Apresentação da } \\
\text { proposta de trabalho à } \\
\text { equipe diretiva e à } \\
\text { professora das turmas onde } \\
\text { será realizada a pesquisa } \\
\text { (turma A e turma B - } \\
\text { CONTROLE). } 18 / 5\end{array}$} & $\begin{array}{c}\text { Conversa } \\
\text { informal; } \\
\text { apresentação de } \\
\text { textos científicos; } \\
\text { demonstração do } \\
\text { funcionamento } \\
\text { dos aplicativos } \\
\text { Plickers e } \\
\text { Zaption. CARTA } \\
\text { DE } \\
\text { APRESENTAÇÃO e } \\
\text { do TERMO DE } \\
\text { CONSENTIMENTO } \\
\text { LIVRE E } \\
\text { ESCLARECIDO }\end{array}$ & $\begin{array}{l}\text { Ligação telefônica; } \\
\text { cópias dos } \\
\text { documentos oficiais } \\
\text { de autorização }\end{array}$ & $\begin{array}{l}\text { Resposta } \\
\text { positiva/ } \\
\text { negativa por } \\
\text { parte da } \\
\text { equipe } \\
\text { diretiva e } \\
\text { pedagógica }\end{array}$ & $\begin{array}{l}\text { Aplicação da } \\
\text { pesquisa na } \\
\text { instituição } \\
\text { selecionada. }\end{array}$ \\
\hline \multicolumn{2}{|c|}{$\begin{array}{l}\text { 3. Planejamento das } \\
\text { atividades. } \mathbf{2 1 , 2 2} \text { e } \mathbf{2 3 / 5}\end{array}$} & $\begin{array}{l}\text { Elaboração das } \\
\text { atividades } \\
\text { virtuais propostas } \\
\text { com uso do } \\
\text { aplicativo } \\
\text { Zaption; } \\
\text { elaboração das } \\
\text { atividades }\end{array}$ & $\begin{array}{c}\text { Computador, } \\
\text { internet, material } \\
\text { didático implantado } \\
\text { pela escola, } \\
\text { aplicativos Zaption e } \\
\text { Plickers. }\end{array}$ & Check List & $\begin{array}{l}\text { Elaboração } \\
\text { das atividades } \\
\text { específicas } \\
\text { para } \\
\text { aprendizagem } \\
\text { híbrida }\end{array}$ \\
\hline
\end{tabular}




\begin{tabular}{|c|c|c|c|c|}
\hline & $\begin{array}{c}\text { presenciais; } \\
\text { elaboração das } \\
\text { atividades } \\
\text { avaliativas. }\end{array}$ & & & \\
\hline $\begin{array}{l}\text { 4. Apresentação da } \\
\text { proposta de trabalho para } \\
\text { os alunos da turma. } 24 / 5\end{array}$ & Roda de conversa & Sala de aula & $\begin{array}{l}\text { Controle de } \\
\text { frequência }\end{array}$ & $\begin{array}{l}\text { Motivação da } \\
\text { turma para } \\
\text { realizar as } \\
\text { atividadades } \\
\text { propostas. }\end{array}$ \\
\hline $\begin{array}{l}\text { 5. Apresentação do prazo } \\
\text { para acesso ao AVA a fim } \\
\text { de realizar as atividades } \\
\text { lá propostas em formato } \\
\text { "Sala de Aula Invertida". } \\
\mathbf{2 4 / 5}\end{array}$ & $\begin{array}{c}\text { Roda de } \\
\text { conversa; } \\
\text { registros do link } \\
\text { de acesso no } \\
\text { quadro de giz da } \\
\text { sala de aula e } \\
\text { atividades em } \\
\text { AVA (Zaption) } \\
\end{array}$ & $\begin{array}{c}\text { Sala de aula, quadro } \\
\text { de giz, atividades em } \\
\text { AVA }\end{array}$ & $\begin{array}{l}\text { Gráfico do } \\
\text { AVA }\end{array}$ & $\begin{array}{c}\text { Realização } \\
\text { das atividades } \\
\text { em AVA }\end{array}$ \\
\hline $\begin{array}{l}\text { 7. Acompanhamento e } \\
\text { análise do gráfico de } \\
\text { produtividade disponível no } \\
\text { aplicativo Zaption.24/5 } \\
\text { (após às 23h) }\end{array}$ & $\begin{array}{l}\text { Acesso ao } \\
\text { aplicativo }\end{array}$ & $\begin{array}{l}\text { Internet; } \\
\text { computador; } \\
\text { aplicativo }\end{array}$ & $\begin{array}{l}\text { Gráfico do } \\
\text { AVA }\end{array}$ & $\begin{array}{l}\text { Levantamento } \\
\text { de } \\
\text { desempenho } \\
\text { individual dos } \\
\text { alunos }\end{array}$ \\
\hline $\begin{array}{l}\text { 8. Propor debate em sala de } \\
\text { aula sobre os assuntos } \\
\text { abordados nas atividades } \\
\text { propostas em AVA } \\
\text { (realizadas fora da sala de } \\
\text { aula e sem a presença do } \\
\text { professor). } 25 / 5\end{array}$ & $\begin{array}{l}\text { Roda de Conversa } \\
\text { e atividades em } \\
\text { "times" } \\
\text { (atividades em } \\
\text { graus de } \\
\text { complexidade } \\
\text { diferentes para } \\
\text { fixação dos } \\
\text { assuntos } \\
\text { trabalhados) }\end{array}$ & $\begin{array}{c}\text { Sala de aula; papel } \\
\text { sulfite; copiadora; } \\
\text { carteiras alinhadas } \\
\text { em } 04 \text { círculos (10 } \\
\text { carteiras em média } \\
\text { para cada círculo) }\end{array}$ & $\begin{array}{l}\text { Desempenho } \\
\text { nas atividades } \\
\text { presenciais }\end{array}$ & $\begin{array}{l}\text { Realização } \\
\text { das atividades } \\
\text { presenciais } \\
\text { em modo } \\
\text { "times" } \\
\text { conforme } \\
\text { análise dos } \\
\text { gráficos de } \\
\text { produtividade } \\
\text { disponíveis } \\
\text { pelo } \\
\text { aplicativo } \\
\text { Zaption }\end{array}$ \\
\hline $\begin{array}{l}\text { 9. Avaliação da } \\
\text { aprendizagem. 30/5 }\end{array}$ & $\begin{array}{c}\text { Uso do aplicativo } \\
\text { Plickers }\end{array}$ & $\begin{array}{c}\text { Celular; aplicativo } \\
\text { Plickers; cartões- } \\
\text { resposta do aplicativo }\end{array}$ & $\begin{array}{l}\text { Gráficos } \\
\text { gerados pelo } \\
\text { aplicativo } \\
\text { Plickers }\end{array}$ & $\begin{array}{c}\text { Aferição do } \\
\text { resultado final } \\
\text { da } \\
\text { aprendizagem }\end{array}$ \\
\hline $\begin{array}{l}10 \text {. Apresentação do } \\
\text { registro do resultado final. } \\
\mathbf{3 1 / 5}\end{array}$ & $\begin{array}{c}\text { Elaboração de } \\
\text { Portfolio }\end{array}$ & $\begin{array}{l}\text { Fotos; gráficos; } \\
\text { relatórios }\end{array}$ & Evidências & $\begin{array}{c}\text { Aferição do } \\
\text { resultado final } \\
\text { da } \\
\text { aprendizagem }\end{array}$ \\
\hline
\end{tabular}


Anexo 2: Música " Estrutura Atômica”

(Disponível em: https://www.youtube.com/watch?v=a-bf9QKCH1g)

Estrutura atômica

Em estrutura atômica

eu vou virar uma fera

Sei que o átomo se divide

Em núcleo e eletrosfera

O núcleo é muito pequeno

Formado por prótons e nêutrons

A eletrosfera é bem maior

Contendo apenas elétrons

Prótons e nêutrons nos dão

A massa que o átomo tem

A eletrosfera determina

O tamanho dele também

Tendo carga positiva

Os prótons nos mostrarão

A que elemento pertence

Um átomo em questão

E esse número de prótons

De cada elemento químico

É representado por $Z$

E chamado número atômico

Em estrutura atômica

eu vou virar uma fera

Sei que o átomo se divide

Em núcleo e eletrosfera

Os nêutrons não têm carga

Mas juntos com os prótons darão

O famoso número de massa

Dos elementos então

E num átomo neutro isolado

No estado fundamental 
O número de prótons e elétrons

Será sempre igual

Elétrons têm carga negativa

Na eletrosfera estão, todavia

Em até sete camadas ou níveis

E subníveis de energia

Em estrutura atômica

eu vou virar uma fera

Sei que o átomo se divide

Em núcleo e eletrosfera 